\title{
In silico Approach to Identify Potent Bioactive Compounds as Inhibitors against the Enoyl-acyl Carrier Protein (acp) Reductase Enzyme of Mycobacterium tuberculosis
}

\author{
Diptendu Sarkar $^{1 \mathbb{D}}$, Arpan Kumar Maiti ${ }^{2 \mathbb{D}}$, Rawaf Alenazy ${ }^{3 \mathbb{C}}$, Babu Joseph ${ }^{3, * \mathbb{C}}$ \\ 1 Department of Microbiology, Ramakrishna Mission Vidyamandira, Belur Marh, Howrah 711202 West Bengal India; \\ diptendu81@gmail.com (D.S.); \\ 2 Department of Zoology, University of North Bengal, Raja Rammohunpur, Darjeeling 734013 West Bengal India; \\ arpankrmaiti@nbu.ac.in (A.K.M.); \\ 3 Department of Clinical Laboratory Sciences, College of Applied Medical Sciences, Shaqra University, Shaqra, Kingdom \\ of Saudi Arabia, ralenazy@su.edu.sa (R.A.), babujosephindia@yahoo.com (B.J.); \\ * Correspondence: babujosephindia@yahoo.com (B.J.);
}

Scopus Author ID 34872374200

Received: 20.09.2021; Revised: 25.10.2021; Accepted: 28.10.2021; Published: 21.11.2021

\begin{abstract}
The enoyl-acyl carrier protein (ACP) reductase (InhA) of Mycobacterium tuberculosis elongates acyl fatty acids, which are progenitors of mycolic acids and that are mycobacterial cell wall parts. The aim is to discover potent therapeutic novel bioactive compounds as enoyl-acyl carrier protein (ACP) reductase (InhA, PDB ID: 4U0J) antagonists using an in silico drug design scheme. Structurebased computerized prediction of drug-receptor interactions. PyRx virtual screening tool was used to conduct molecular docking investigations on enoyl-ACP reductase. A target-based ligand selection strategy to choose ligand compounds was employed. The ligand structure was chosen using LEA3DCNRS. Medication data set that was approved by the FDA: 2028 molecule (s) were used in the study. Around 27 bioactive molecules can bind to the 4U0J, with docking scores ranging from -6.2 to -11.2 $\mathrm{Kcal} / \mathrm{mol}$. Compound CHEMBL441373 was shown to have the highest acceptable docking energy ($11.1 \mathrm{Kcal} / \mathrm{mol}$ ), making it a good candidate for a cell wall protein inhibitor (4U0J) that should be investigated further in vivo and in vitro. The anti-mycobacterial ability of triazole scaffolding in a new therapeutic was determined. Compound CHEMBL441373 is located to possess high docking energy ($11.1 \mathrm{Kcal} / \mathrm{mol}$ ) and is shown as a suitable molecule of cell wall protein inhibitor (4U0J).
\end{abstract}

Keywords: Peptidoglycan; antagonists; cell wall protein; bioactive molecule; docking energy.

(C) 2021 by the authors. This article is an open-access article distributed under the terms and conditions of the Creative Commons Attribution (CC BY) license (https://creativecommons.org/licenses/by/4.0/).

\section{Introduction}

Tuberculosis is a respiratory ailment caused by Mycobacterium tuberculosis. This bacterium is found in the lungs, but if left untreated, it can spread to other parts of the body. From the mouth or air, droplets from a sick individual can spread this bacterium to healthy people [1]. A combination of antibiotics is used to treat this infection. The cell wall targeting antibiotics could be beneficial to treat this bacteria and stop their replication in the lungs [2]. This disease is typically treated over a period of 6-9 months. Historically, most drugs were discovered either by selecting the relevant element in traditional medicines or by chance [3]. Realizing how sickness and diseases are driven at the molecular and physiological levels, and selecting appropriate characteristics that tend upon the knowledge, has been a unique 
technique. Molecular docking is a technique for determining how one molecule should interact with another when they are coupled together to form a stable compound [4]. Based on the preferred orientation, one can anticipate the degree of association or ligands between two molecules using selected features. After two molecules have been docked, scoring methods are used to assess the strength of their non-covalent interaction, which is also known as binding affinity [5]. Molecular docking has grown in importance as a drug discovery tool.

Mycobacterium tuberculosis is the main causative organism of human tuberculosis and the world's leading cause of death due to the higher pathogenic nature of this bacteria. Tuberculosis is responsible for approximately $7 \%$ of all deaths in developing countries and around $26 \%$ of preventable deaths worldwide [1]. There is an urgent need to develop inorganic or organic antitubercular medicines due to the diminished likely impact of treatments due to the rise of multidrug-resistant tuberculosis and HIV co-infection [6]. The main drawbacks of therapeutic medications for mycobacterial infections are the lengthy treatment regimen with a type of medication with a cytotoxic effect and the emergence of multidrug-resistant bacteria and fungi, which generate a high mortality rate in immunocompetent people [7]. The necessity for effective treatment has motivated investigation into the formulation and synthesis of new chemicals that can combat mycobacterial infections. Because of the emergence of antibioticresistant strains, the development of compounds with good antitubercular action is becoming increasingly important in tuberculosis research [8].

The enoyl-acyl carrier protein (ACP) reductase (InhA) (Fig. 1) of Mycobacterium tuberculosis has been suggested as a promising candidate for antitubercular medicines [9]. InhA belongs to the NADH-dependent enoyl-ACP (CoA) reductase enzyme family. InhA elongates acyl fatty acids, which are progenitors of mycolic acids and mycobacterial cell wall components. A structure-based computerized simulation of ligand-receptor associations was used in this study. The purpose of this study is to find potentially bioactive molecules as enoylacyl carrier protein (ACP) reductase (InhA) antagonists using an in silico drug design approach.

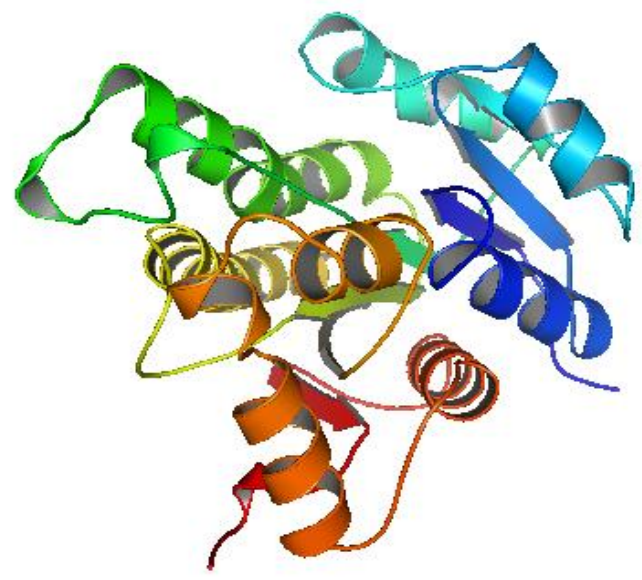

Figure 1. The 3D crystal structure of enoyl-acyl carrier protein (ACP) reductase (InhA), PDB ID: 4U0J.

\section{Materials and Methods}

The in-silico study was carried out by using PyRx virtual screening tool. Protein preparation was carried out by Biovia discovery studio software version 2021. Ligand preparation grid generation and receptor-ligand docking were all carried out by PyRx in the build process. The Swiss ADME server was used for drug-likeness prediction of all compounds selected for the study. 


\subsection{Selection of target protein.}

The enoyl-acyl carrier protein (ACP) reductase (InhA), PDB ID: 4U0J, with 1.62 resolution and one protein chain (A), was retrieved from the Protein Data Bank (PDB) and utilized for docking.

\subsection{Selection of ligand molecules.}

For a selection of ligand molecules, we used a target-based ligand selection approach. LEA3D-CNRS (https://chemoinfo.ipmc.cnrs.fr/LEA3D/index.html) was used for selecting ligand structure [10]. FDA-approved drug data set: 2028 molecule(s) was used. Hereafter uploading the prepared protein structure provided $\mathrm{X}, \mathrm{Y}$, and $\mathrm{Z}$ grid coordinates information. This information was received from Biovia discovery studio software once uploaded unprepared protein with a bound ligand. Result received in the provided mail ID within 24 hours. Best ligand structure selected based on the population means score in \%. Structures of all the bioactive compounds were downloaded from ChEMBL in SDF format (Chemical structure and CHEMBL ID of all 27 components along with two reference molecules are listed in Table 1). With all the structures, further ADME predictions were carried out using SWISS ADME to filter all bioactive compounds based on the Lipinski rule of five [11].

Table 1. CHEMBL ID and a molecular formula of selected ligands.

\begin{tabular}{|c|c|c|}
\hline S. No & Compound ID & Molecular formula \\
\hline 1 & CHEMBL385214 & $\mathrm{C}_{17} \mathrm{H}_{21} \mathrm{BrN}_{2} \mathrm{O}_{2}$ \\
\hline 2 & CHEMBL385294 & $\mathrm{C}_{17} \mathrm{H}_{20} \mathrm{~F}_{2} \mathrm{~N}_{2} \mathrm{O}_{2}$ \\
\hline 3 & CHEMBL217588 & $\mathrm{C}_{17} \mathrm{H}_{21} \mathrm{C}_{1} \mathrm{~N}_{2} \mathrm{O}_{2}$ \\
\hline 4 & CHEMBL387186 & $\mathrm{C}_{19} \mathrm{H}_{26} \mathrm{~N}_{2} \mathrm{O}_{2}$ \\
\hline 5 & CHEMBL216807 & $\mathrm{C}_{17} \mathrm{H}_{20} \mathrm{C}_{12} \mathrm{~N}_{2} \mathrm{O}_{2}$ \\
\hline 6 & CHEMBL411394 & $\mathrm{C}_{18} \mathrm{H}_{21} \mathrm{~F}_{3} \mathrm{~N}_{2} \mathrm{O}_{2}$ \\
\hline 7 & CHEMBL387284 & $\mathrm{C}_{20} \mathrm{H}_{28} \mathrm{~N}_{2} \mathrm{O}_{2}$ \\
\hline 8 & CHEMBL213872 & $\mathrm{C}_{25} \mathrm{H}_{29} \mathrm{~N}_{3} \mathrm{O}_{2}$ \\
\hline 9 & CHEMBL441373 & $\mathrm{C}_{23} \mathrm{H}_{26} \mathrm{~N}_{2} \mathrm{O}_{2}$ \\
\hline 10 & CHEMBL216339 & $\mathrm{C}_{19} \mathrm{H}_{20} \mathrm{~F}_{6} \mathrm{~N}_{2} \mathrm{O}_{2}$ \\
\hline 11 & CHEMBL425259 & $\mathrm{C}_{18} \mathrm{H}_{23} \mathrm{C}_{1} \mathrm{~N}_{2} \mathrm{O}_{2}$ \\
\hline 12 & CHEMBL424724 & $\mathrm{C}_{24} \mathrm{H}_{28} \mathrm{~N}_{2} \mathrm{O}_{2}$ \\
\hline 13 & CHEMBL217852 & $\mathrm{C}_{24} \mathrm{H}_{26} \mathrm{~N}_{2} \mathrm{O}_{2}$ \\
\hline 14 & CHEMBL216642 & $\mathrm{C}_{17} \mathrm{H}_{15} \mathrm{C}_{1} \mathrm{~N}_{2} \mathrm{O}_{2}$ \\
\hline 15 & CHEMBL371268 & $\mathrm{C}_{19} \mathrm{H}_{29} \mathrm{FN}_{2} \mathrm{O}$ \\
\hline 16 & CHEMBL2441664 & $\mathrm{C}_{23} \mathrm{H}_{33} \mathrm{~N}_{3} \mathrm{O}$ \\
\hline 17 & CHEMBL207085 & $\mathrm{C}_{29} \mathrm{H}_{39} \mathrm{~N}_{3} \mathrm{O}_{2}$ \\
\hline 18 & CHEMBL386324 & $\mathrm{C}_{18} \mathrm{H}_{20} \mathrm{BrF}_{3} \mathrm{~N}_{2} \mathrm{O}_{2}$ \\
\hline 19 & CHEMBL2441646 & $\mathrm{C}_{19} \mathrm{H}_{27} \mathrm{~N}_{3} \mathrm{O}$ \\
\hline 20 & CHEMBL2441653 & $\mathrm{C}_{22} \mathrm{H}_{33} \mathrm{~N}_{3} \mathrm{O}$ \\
\hline 21 & CHEMBL384149 & $\mathrm{C}_{18} \mathrm{H}_{23} \mathrm{C}_{1} \mathrm{~N}_{2} \mathrm{O}_{3}$ \\
\hline 22 & CHEMBL2441650 & $\mathrm{C}_{23} \mathrm{H}_{35} \mathrm{~N}_{3} \mathrm{O}$ \\
\hline 23 & CHEMBL217499 & $\mathrm{C}_{19} \mathrm{H}_{24} \mathrm{~N}_{2} \mathrm{O}_{2}$ \\
\hline 24 & CHEMBL386990 & $\mathrm{C}_{24} \mathrm{H}_{31} \mathrm{~N}_{3} \mathrm{O}_{2}$ \\
\hline 25 & CHEMBL214285 & $\mathrm{C}_{25} \mathrm{H}_{33} \mathrm{~N}_{3} \mathrm{O}_{2}$ \\
\hline 26 & CHEMBL424903 & $\mathrm{C}_{24} \mathrm{H}_{28} \mathrm{~N}_{2} \mathrm{O}_{3}$ \\
\hline 27 & CHEMBL385168 & $\mathrm{C}_{22} \mathrm{H}_{29} \mathrm{~N}_{3} \mathrm{O}$ \\
\hline 28 & $\begin{array}{l}\text { CHEMBL374478 } \\
\text { (Rifampicin) }\end{array}$ & $\mathrm{C}_{43} \mathrm{H}_{58} \mathrm{~N}_{4} \mathrm{O}_{12}$ \\
\hline 29 & $\begin{array}{c}\text { CHEMBL3989817 } \\
\text { (Pyrrolidine carboxamides) }\end{array}$ & $\mathrm{C}_{41} \mathrm{H}_{69} \mathrm{NO}_{14}$ \\
\hline
\end{tabular}

\subsection{Molecular docking investigation.}

Molecular docking analysis was performed with a target like enoyl-ACP reductase by using PyRx virtual screening tool [12]. This tool used Auto Dock for docking purposes. The 
prepared protein structure was uploaded as a macromolecule, and then bioactive compounds (ligand) one by one was selected. The software first minimized ligand energy and then converted it into Auto Dock ligand format (pdbqt). Finally, started blind docking after covering the entire protein structure under the grid box to screen best fitted bioactive compounds based on the energy value. Each simulation was conducted roughly ten times, resulting in ten docked conformations. As a result, the least energy configurations were deemed to be the highest binding conformations. Finally, the best ligand and protein docked complex was analyzed by Biovia discovery studio [13].

\section{Results and Discussion}

The 4U0J (Enoyl-[acyl-carrier-protein] reductase [NADH]) is a $\sim 269$ amino acid long main protease of $29.50 \mathrm{kD}$, the crystal structure with a resolution of $1.62 \AA$ has been elucidated. Different bioactive substances were subjected to in silico molecular analysis. The physiochemical parameters such as hydrogen bond acceptor, hydrogen bond donor, number of rotatable bonds, molecular weight, and so on were anticipated and tested for drug violations. The "Lipinski rule of five" was followed by all of these compounds (Table 2).

Table 2. Lipinski rule-related information of selected compounds studied along with reference compounds rifampicin and pyrrolidine carboxamides.

\begin{tabular}{|c|c|c|c|c|c|c|c|}
\hline Compound ID & $\begin{array}{l}\text { Mol wt } \\
(\mathrm{g} / \mathrm{mol})\end{array}$ & $\begin{array}{c}\log P \\
o / w\end{array}$ & LogS & $\begin{array}{l}\text { H donor } \\
(\text { nON })\end{array}$ & $\begin{array}{l}\text { H acceptor } \\
\text { (nOHNH) }\end{array}$ & $\begin{array}{l}\text { No. of rotatable } \\
\text { bonds (nrotab) }\end{array}$ & $\begin{array}{l}\text { Lipinski } \\
\text { violation }\end{array}$ \\
\hline CHEMBL 385214 & 365.26 & 2.91 & -3.79 & 1 & 2 & 4 & 0 \\
\hline CHEMBL 385294 & 332.25 & 2.68 & -3.2 & 1 & 4 & 4 & 0 \\
\hline CHEMBL 217588 & 320.81 & 2.78 & -3.47 & 1 & 2 & 4 & 0 \\
\hline CHEMBL 387186 & 314.42 & 3.13 & -3.49 & 1 & 2 & 4 & 0 \\
\hline CHEMBL 216807 & 355.26 & 2.91 & -4.08 & 1 & 2 & 4 & 0 \\
\hline CHEMBL 411394 & 354.37 & 2.85 & -3.76 & 5 & 1 & 5 & 0 \\
\hline CHEMBL 387284 & 328.45 & 3.24 & -3.75 & 2 & 1 & 5 & 0 \\
\hline CHEMBL 213872 & 403.52 & 3.62 & -4.73 & 2 & 1 & 5 & 0 \\
\hline CHEMBL 441373 & 362.46 & 3.25 & -4.42 & 2 & 1 & 5 & 0 \\
\hline CHEMBL 216339 & 422.36 & 3.04 & -4.64 & 8 & 1 & 6 & 0 \\
\hline CHEMBL 425259 & 334.84 & 3.09 & -3.78 & 2 & 1 & 4 & 0 \\
\hline CHEMBL 424724 & 376.49 & 3.39 & -4.62 & 2 & 1 & 6 & 0 \\
\hline CHEMBL 217852 & 374.48 & 3.33 & -4.44 & 2 & 1 & 5 & 0 \\
\hline CHEMBL 371268 & 319.45 & 3.83 & -3.63 & 3 & 0 & 9 & 0 \\
\hline CHEMBL 2441664 & 367.53 & 4.01 & -4.72 & 2 & 1 & 5 & 0 \\
\hline CHEMBL 207085 & 461.64 & 4.52 & -5.03 & 3 & 0 & 10 & 0 \\
\hline CHEMBL 386324 & 320.21 & 3.23 & -4.67 & 5 & 1 & 5 & 0 \\
\hline CHEMBL 2441646 & 313.44 & 3.27 & -3.43 & 2 & 1 & 5 & 0 \\
\hline CHEMBL 2441653 & 355.52 & 3.89 & -4.66 & 2 & 1 & 6 & 0 \\
\hline CHEMBL 384149 & 350.84 & 3.37 & -3.56 & 3 & 1 & 5 & 0 \\
\hline CHEMBL 2441650 & 369.54 & 4.09 & -4.8 & 2 & 1 & 5 & 0 \\
\hline CHEMBL 217499 & 312.41 & 3.02 & -3.71 & 2 & 0 & 3 & 0 \\
\hline CHEMBL 386990 & 393.52 & 3.13 & -3.27 & 3 & 1 & 10 & 0 \\
\hline CHEMBL 214285 & 407.55 & 3.77 & -4.02 & 3 & 1 & 11 & 0 \\
\hline CHEMBL 424903 & 392.49 & 3.06 & -4.35 & 3 & 1 & 7 & 0 \\
\hline CHEMBL 385168 & 351.49 & 3.26 & -3.45 & 3 & 1 & 8 & 0 \\
\hline $\begin{array}{l}\text { CHEMBL } 374478 \\
\text { (Rifampicin) }\end{array}$ & 856.20 & 0.00 & -5.93 & 14 & 9 & 18 & 3 \\
\hline
\end{tabular}

The molecular docking technique was used to explore, predict and understand the protein or enzyme interactions with the selected ligand library; and to visualize the probable binding. Analogs were docked with receptors (4U0J) using the PyRx virtual screening tool, which used Autodock 4.2.1, and the binding energy and interacting residues were obtained 
(Table 3). All 3D and 2D diagrams of the respective ligand with protein are depicted in Fig 228.

Table 3. Docking-related information of selected compounds studied along with reference compounds rifampicin and pyrrolidine carboxamides.

\begin{tabular}{|c|c|c|c|c|c|}
\hline SI No & Compound ID & Interacting residue & $\begin{array}{l}\text { No of } \mathrm{H} \text { bonds } \\
\text { in interaction }\end{array}$ & $\begin{array}{c}\text { Interaction energy } \\
(\text { Kcal/mol })\end{array}$ & $\begin{array}{l}\text { Fig } \\
\text { No }\end{array}$ \\
\hline 1 & CHEMBL385214 & Val65, Ile122, Phe41, Ile95, Gly96, Thr196, Ala198 & 1 & -8.8 & 2 \\
\hline 2 & CHEMBL385294 & $\begin{array}{l}\text { Ile122, Val65, Phe41, Ile95, Gly14, Gly96, Ile21, } \\
\text { Thr196 }\end{array}$ & 2 & -9.9 & 3 \\
\hline 3 & CHEMBL217588 & Ile215, Ala157, Pro193, tyr158, Ile21 & 1 & -9.2 & 4 \\
\hline 4 & CHEMBL387186 & Ala198, Gly96, Ile122, Phe41, Ile95, Val65 & 1 & -9.0 & 5 \\
\hline 5 & CHEMBL216807 & Ala157, Ile215, Pro193, Tyr158, Met147, Ile21 & 1 & -9.2 & 6 \\
\hline 6 & CHEMBL411394 & Ile194, Met147, Ile215, Ile218, Tyr158, Met199 & 2 & -9.4 & 7 \\
\hline 7 & CHEMBL387284 & $\begin{array}{l}\text { Met199, Tyr158, Leu218, Phe149, Ile215, Met161, } \\
\text { Ile194, Ile21, Met147 }\end{array}$ & 1 & -8.4 & 8 \\
\hline 8 & CHEMBL213872 & Met147, Gly96, Val65, Ile95, Ile122, Phe41 & 1 & -9.8 & 9 \\
\hline 9 & CHEMBL441373 & $\begin{array}{l}\text { Ala198, Leu197, Thr196, Gly96, Ile95, Phe41, Ile122, } \\
\text { Val65 }\end{array}$ & 2 & -10.8 & 10 \\
\hline 10 & CHEMBL216339 & $\begin{array}{l}\text { Ile21, Ser20, Ala198, Ser94, Glu14, Ile16, Ile15, } \\
\text { Phe41, Ile95, Gly96 }\end{array}$ & 5 & -10.2 & 11 \\
\hline 11 & CHEMBL425259 & $\begin{array}{l}\text { Phe41, Ile122, Ile95, Val65, Gly14, Ile21, Met147, } \\
\text { Gly96 }\end{array}$ & 2 & -9.6 & 12 \\
\hline 12 & CHEMBL424724 & $\begin{array}{l}\text { Thr196, Met199, Gly14, Ile16, Phe41, Ile122, Val65, } \\
\text { Gly96, Ile95, Ser20 }\end{array}$ & 3 & -11.1 & 13 \\
\hline 13 & CHEMBL217852 & Phe149, Pro193, Met199, Ala157, Ile215, Gly96, Ile21 & 0 & -10.6 & 14 \\
\hline 14 & CHEMBL216642 & $\begin{array}{l}\text { Ile95, Val65, Ile122, Phe41, Gly96, Gly14, Ser94, } \\
\text { Thr196, }\end{array}$ & 3 & -9.7 & 15 \\
\hline 15 & CHEMBL371268 & Ilr21, Phe149, Leu218, Ile215, Tyr158, Lys165 & 2 & -6.8 & 16 \\
\hline 16 & CHEMBL2441664 & Phe149, Ile21, Ala191, Met199, Phe149 & 0 & -9.2 & 17 \\
\hline 17 & CHEMBL207085 & Phe41, Ala198, Ile16, Ile95, Ile122, Val65, & 0 & -9.8 & 18 \\
\hline 18 & CHEMBL386324 & Ala157, Ile215, Met147, Ile21, Ser94, Tyr158 & 2 & -9.5 & 19 \\
\hline 19 & CHEMBL2441646 & Phe149, Ile21, Ala191, Met199 & 0 & -8.6 & 20 \\
\hline 20 & CHEMBL2441653 & $\begin{array}{l}\text { Ala157, Ile215, Tyr158, Pro193, Met199, Ile21, } \\
\text { Phe149 }\end{array}$ & 0 & -9.1 & 21 \\
\hline 21 & CHEMBL384149 & $\begin{array}{l}\text { Ser20, Gly96, Val65, Phe41, Ile122, Ile95, Gly14, } \\
\text { Met147, Ile16, Ile21, }\end{array}$ & 3 & -9.5 & 22 \\
\hline 22 & CHEMBL2441650 & Gly96, Ile95, Phe41, Ile122, Val65, Val16, Ile21, & 1 & -9.5 & 23 \\
\hline 23 & CHEMBL217499 & Gly96, Ile122, Phe41, Val65, Ile95, Ser94, Ile21 & 0 & -9.9 & 24 \\
\hline 24 & CHEMBL386990 & $\begin{array}{l}\text { Phe41, Ile95, Val65, Ile122, Ile21, Leu197, Thr196, } \\
\text { Ser20 }\end{array}$ & 2 & -9.0 & 25 \\
\hline 25 & CHEMBL214285 & $\begin{array}{l}\text { Ile215, Leu218, Met199, Phe149, Ala198, Thr196, } \\
\text { Lys165 }\end{array}$ & 1 & -9.0 & 26 \\
\hline 26 & CHEMBL424903 & Met147, Gly96, Ile122, Phe41, Ile95, Gly14, Ile21 & 2 & -9.9 & 27 \\
\hline 27 & CHEMBL385168 & Ile21, Ile122, Ile95, Val65, Phe41, Ile16, Ala198, & 0 & -8.8 & 28 \\
\hline 28 & $\begin{array}{l}\text { CHEMBL } 374478 \\
\text { (Rifampicin) }\end{array}$ & Thr196, Ala198, Phe97, Met98 & 1 & -10.8 & 29 \\
\hline 29 & $\begin{array}{l}\text { CHEMBL3989817 } \\
\text { (Pyrrolidine } \\
\text { carboxamides) }\end{array}$ & Ile215, Ala157, Tyr158, Ile21, Met147 & 1 & -8.7 & 30 \\
\hline
\end{tabular}
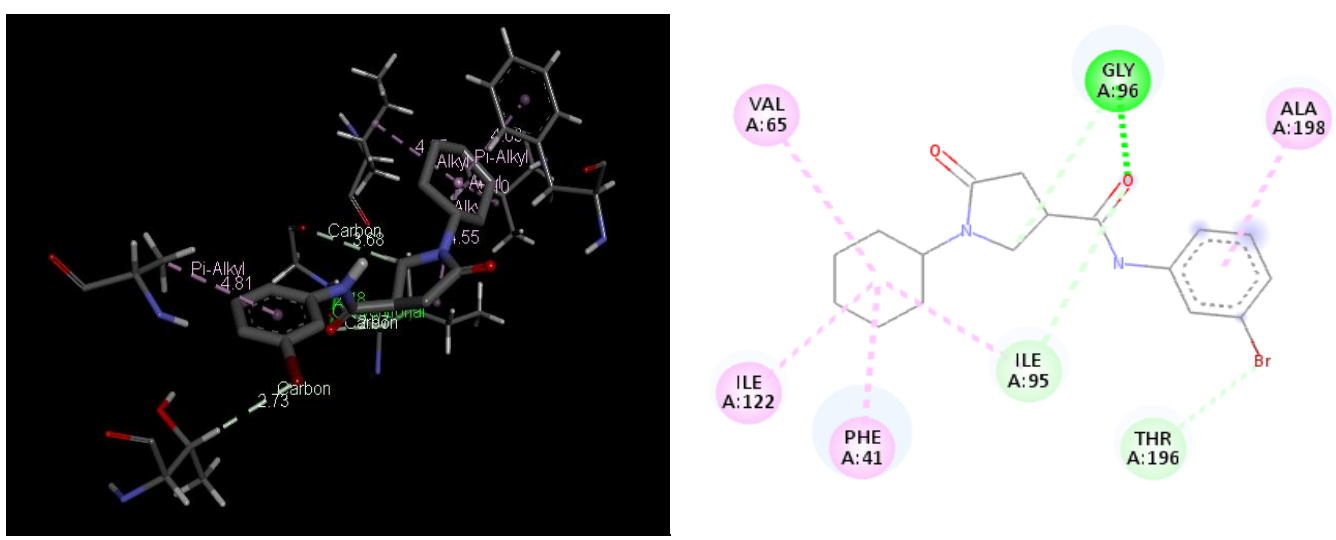

Figure 2. 3D and 2D diagram of CHEMBL385214 interaction with 4U0J. 

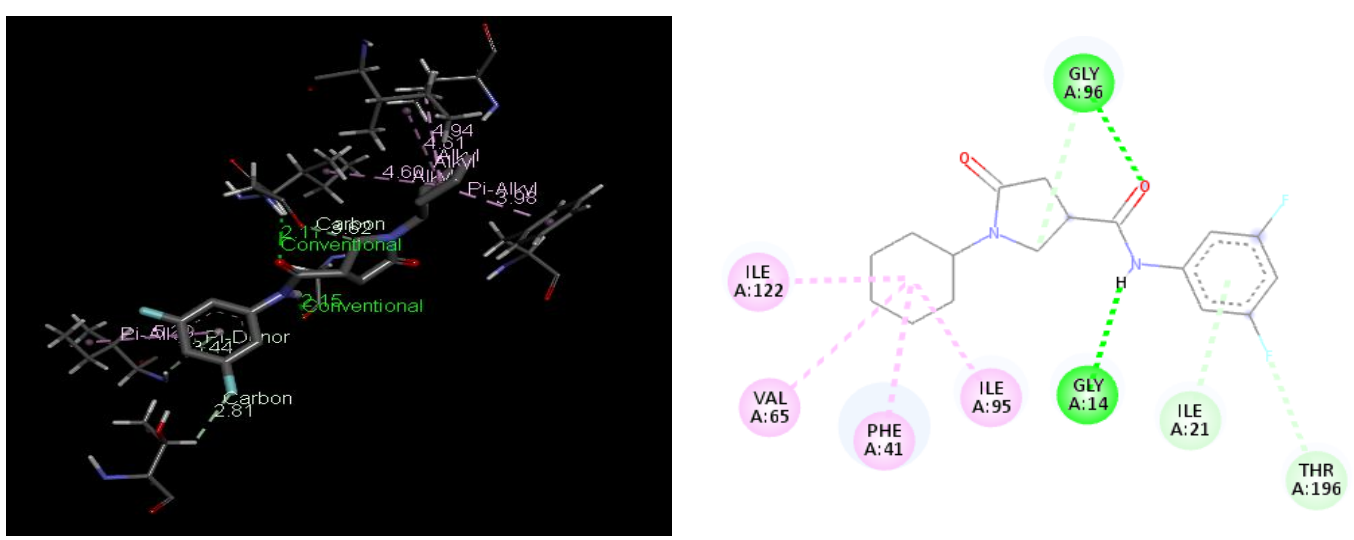

Figure 3. 3D and 2D diagram of CHEMBL385294 interaction with 4U0J.
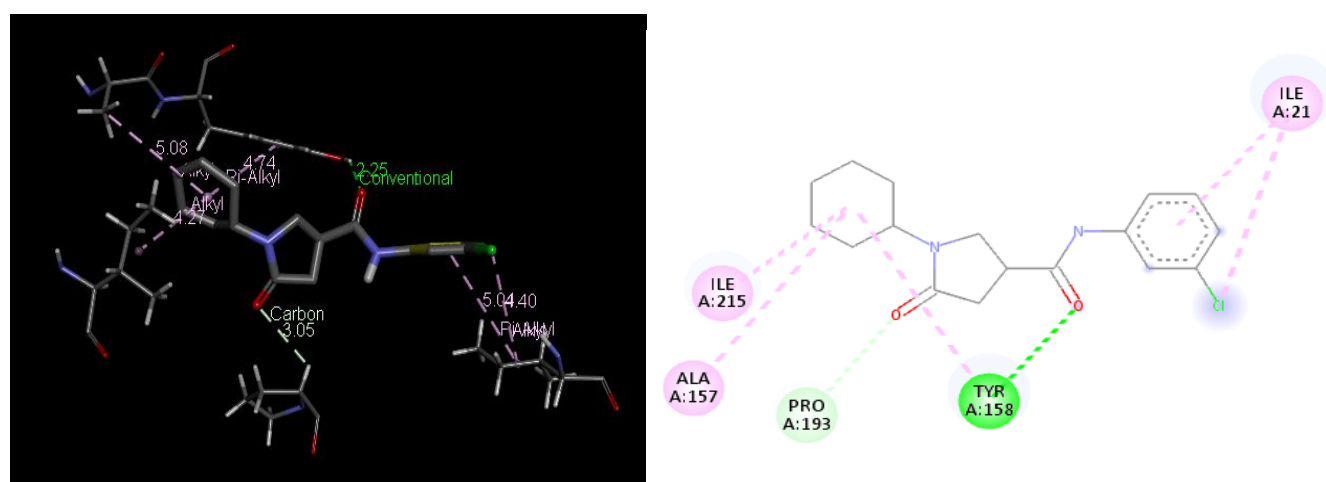

Figure 4. 3D and 2D diagram of CHEMBL217588 interaction with 4U0J.
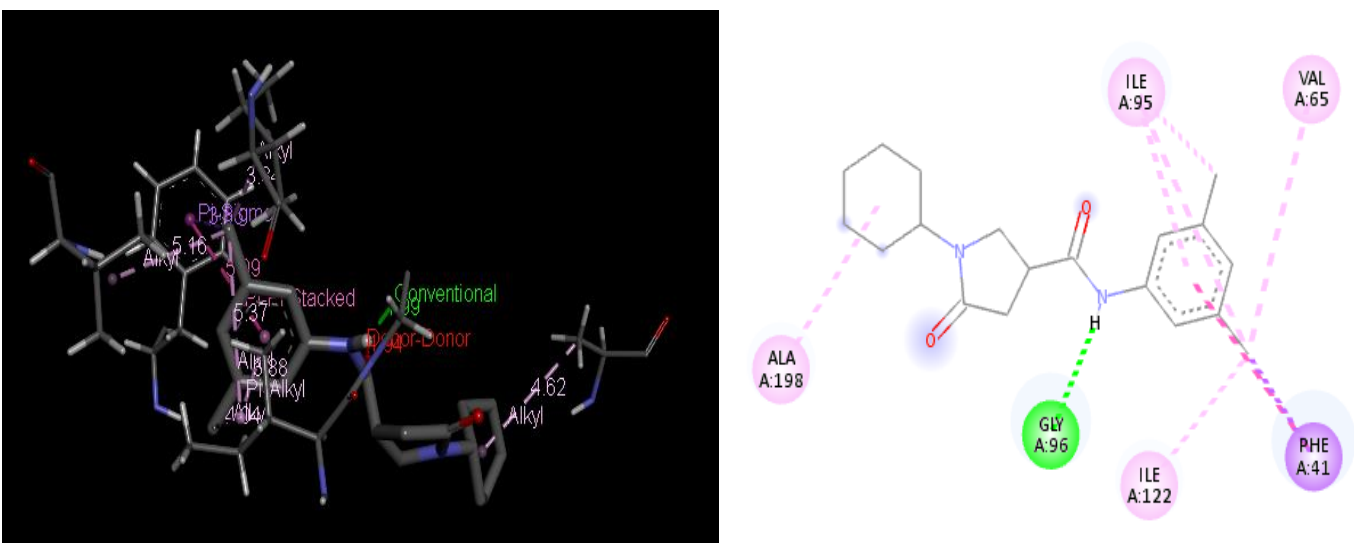

Figure 5. 3D and 2D diagram of CHEMBL387186 interaction with 4U0J.
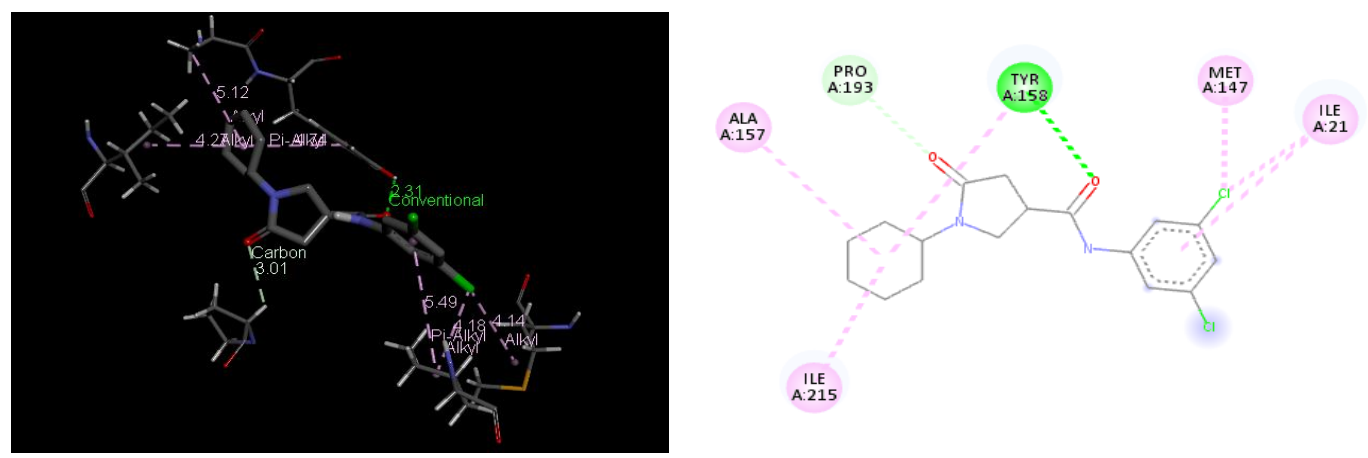

Figure 6. 3D and 2D diagram of CHEMBL216807 interaction with 4U0J. 

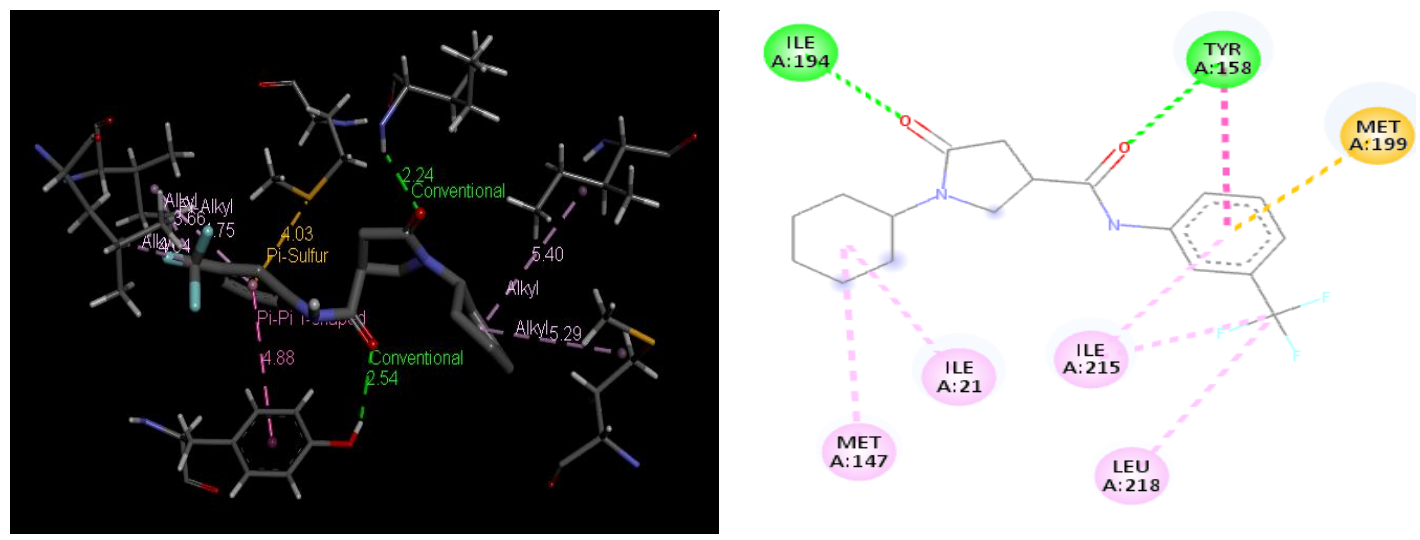

Figure 7. 3D and 2D diagram of CHEMBL411394 interaction with 4U0J.
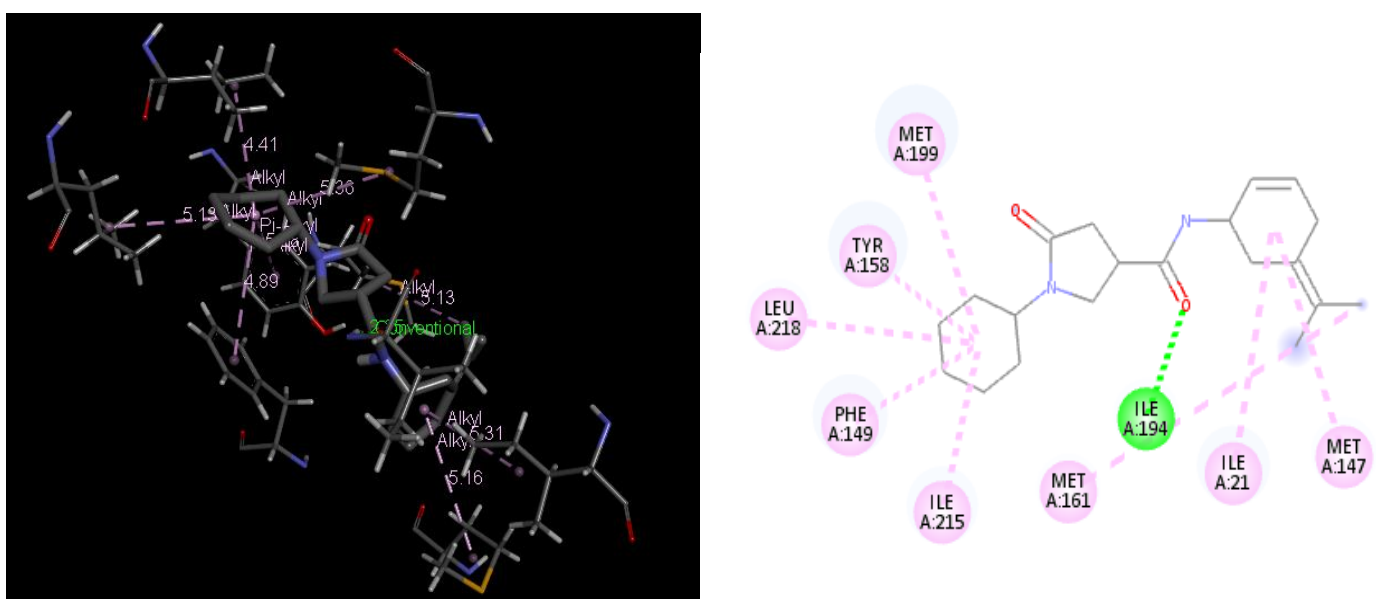

Figure 8. 3D and 2D diagram of CHEMBL387284 interaction with 4U0J.
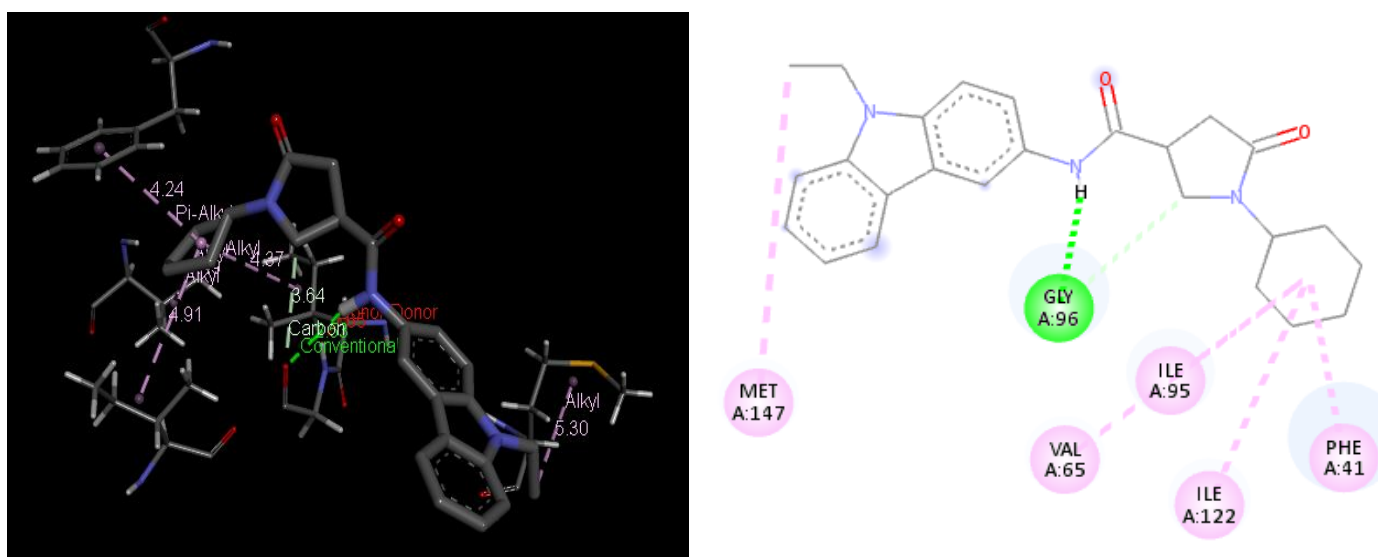

Figure 9. 3D and 2D diagram of CHEMBL213872 interaction with 4U0J.
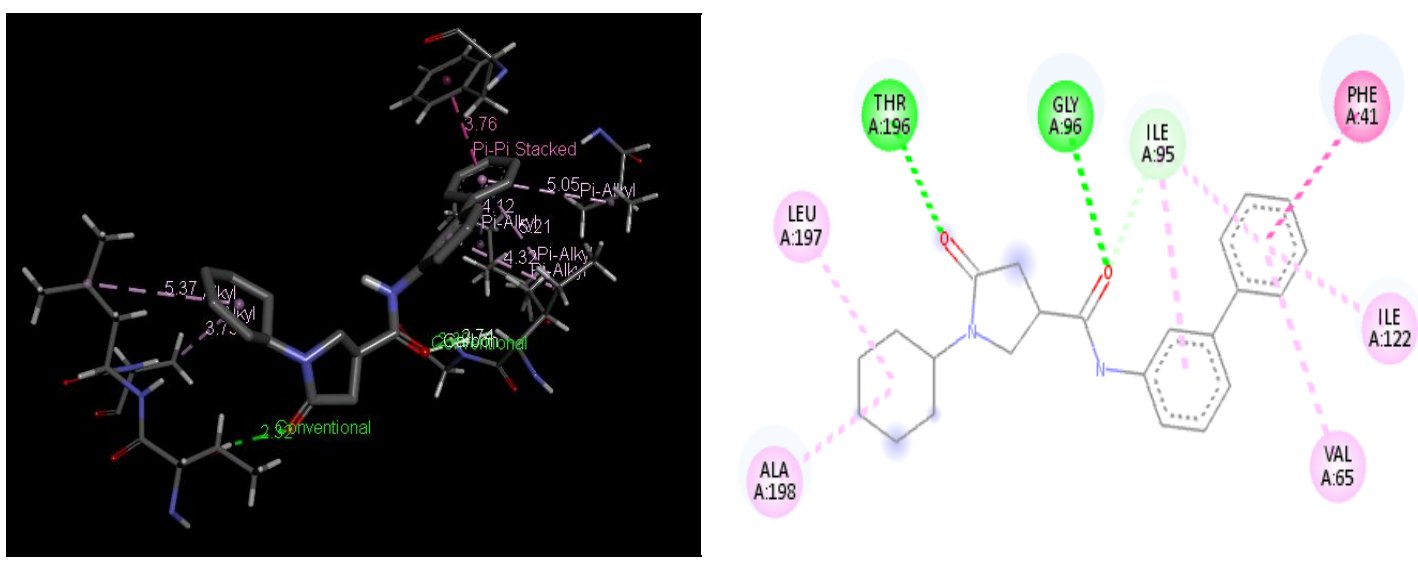

Figure 10. 3D and 2D diagram of CHEMBL441373 interaction with 4U0J. 

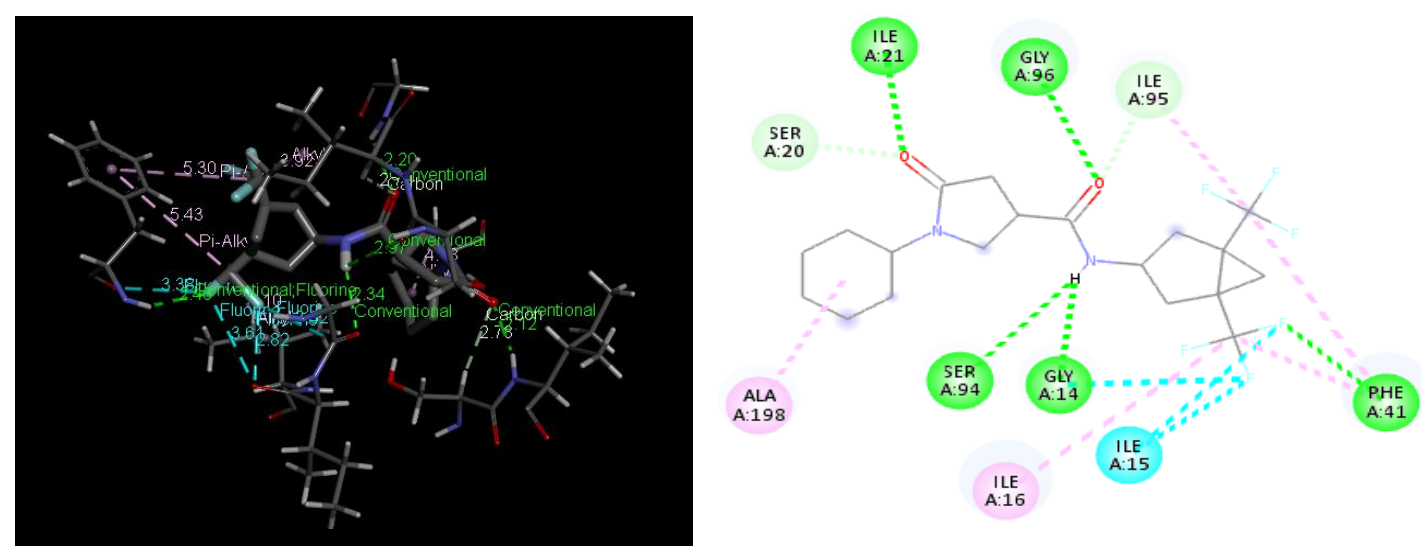

Figure 11. 3D and 2D diagram of CHEMBL216339 interaction with 4U0J.
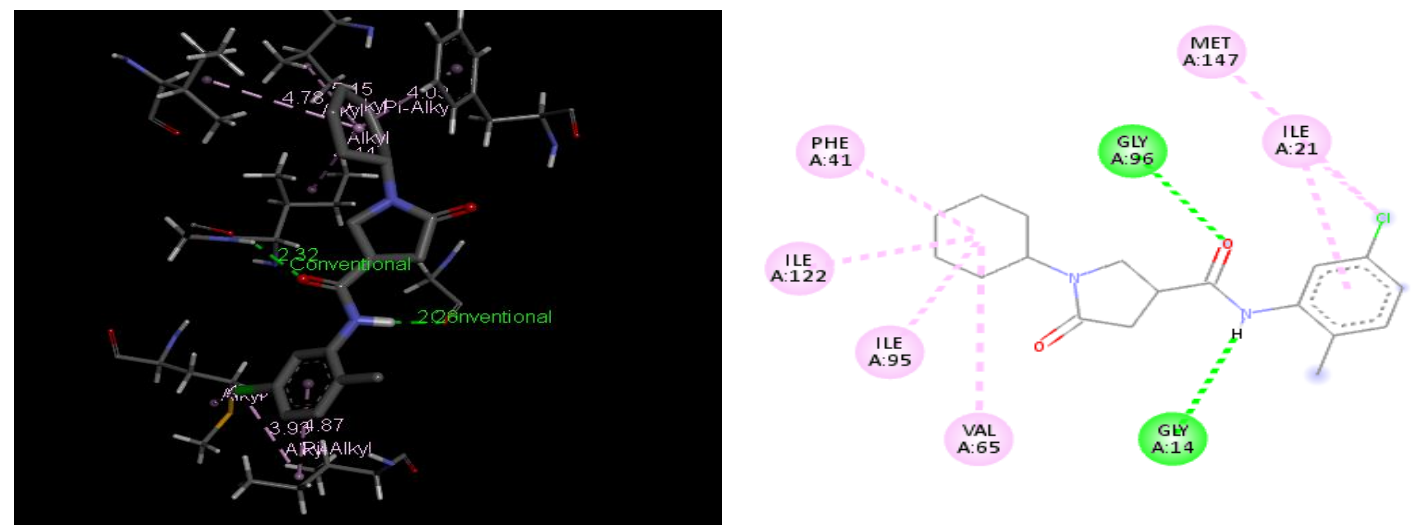

Figure 12. 3D and 2D diagram of CHEMBL425259 interaction with 4U0J.
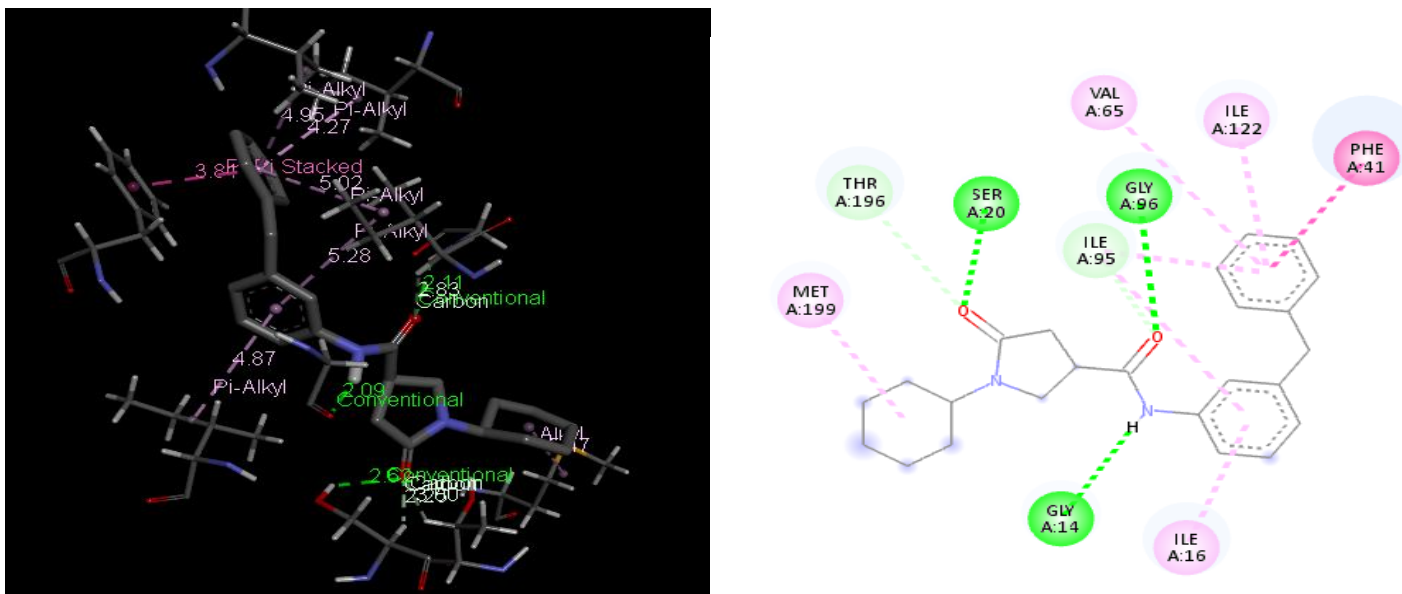

Figure 13. 3D and 2D diagram of CHEMBL424724 interaction with 4U0J.
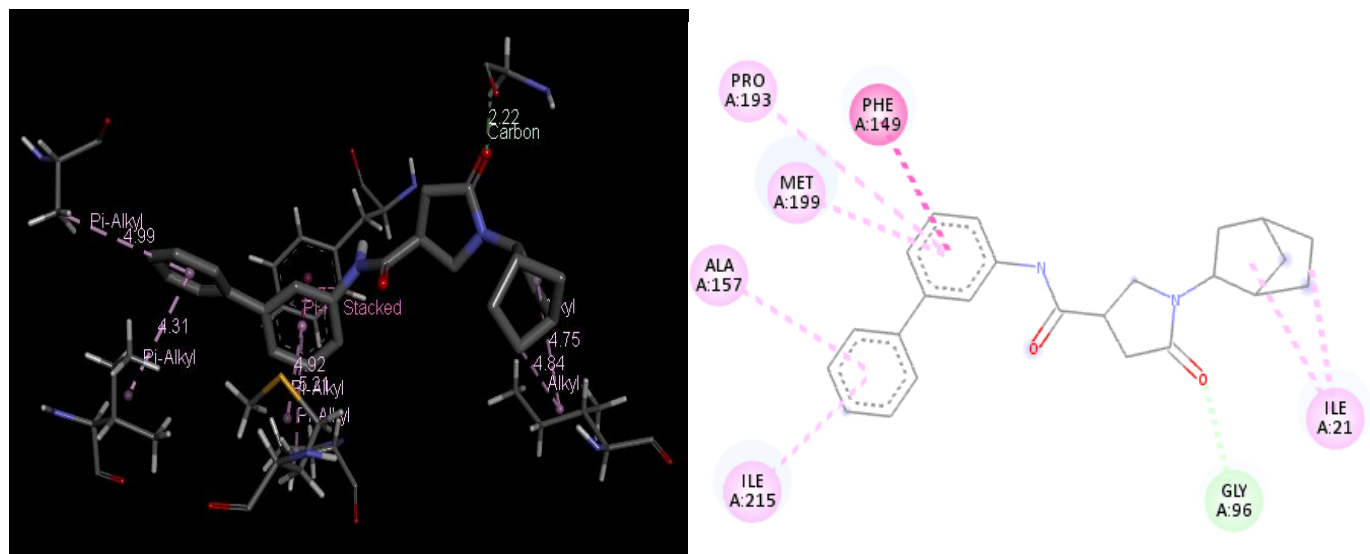

Figure 14. 3D and 2D diagram of CHEMBL217852 interaction with 4U0J. 

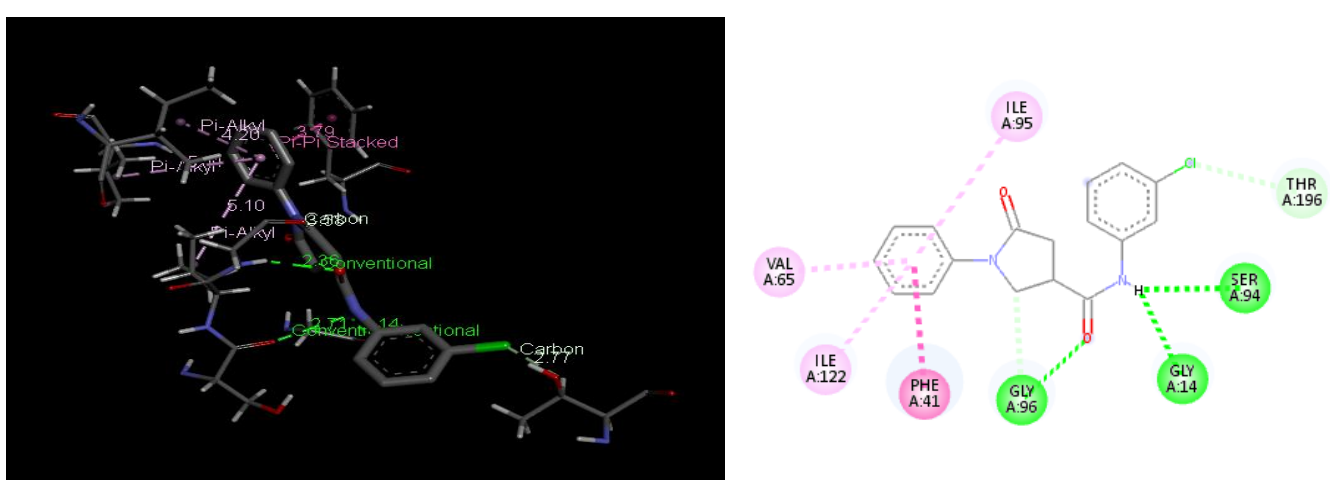

Figure 15. 3D and 2D diagram of CHEMBL216642 interaction with 4U0J.
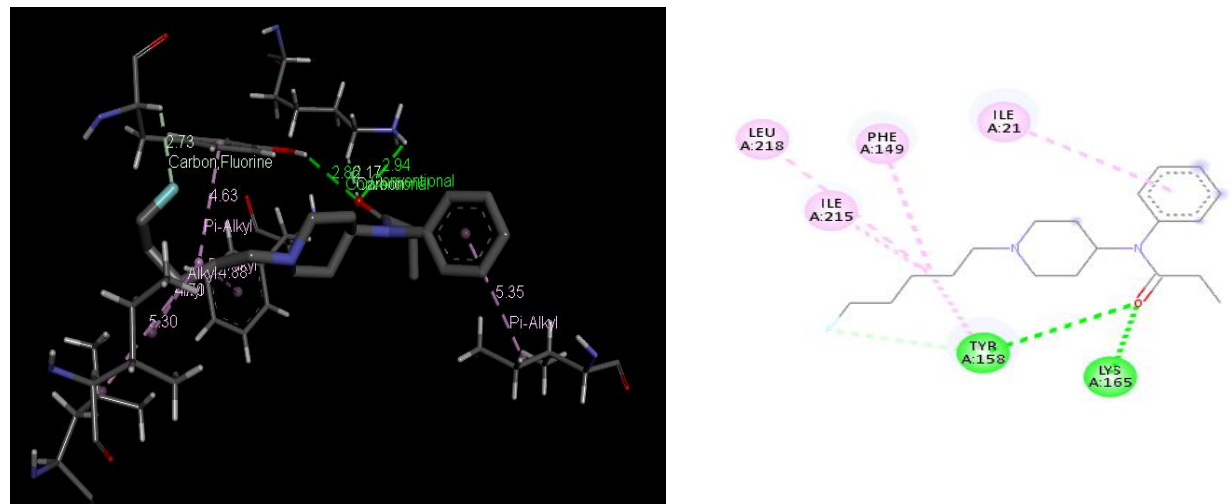

Figure 16. 3D and 2D diagram of CHEMBL371268 interaction with 4U0J.
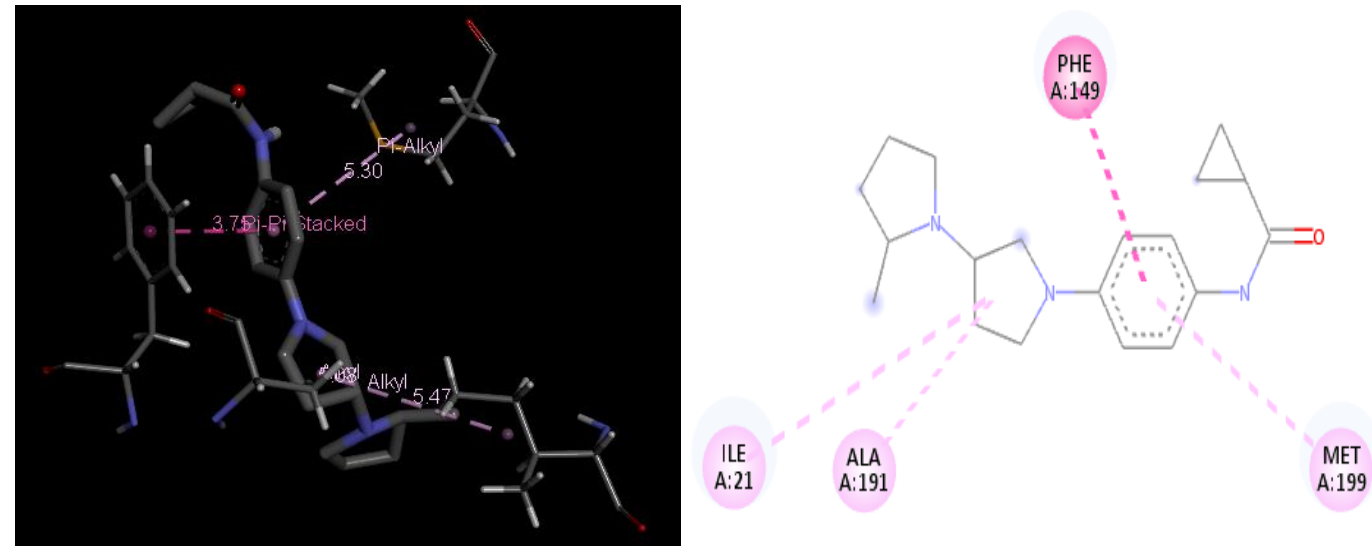

Figure 17. 3D and 2D diagram of CHEMBL2441646 interaction with 4U0J.
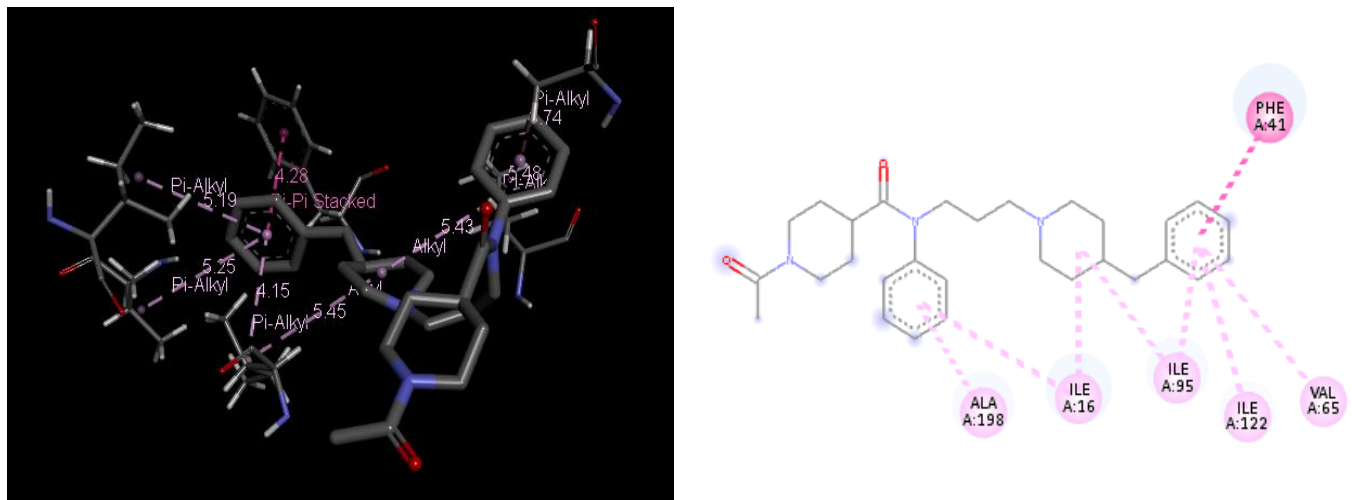

Figure 18. 3D and 2D diagram of CHEMBL207085 interaction with 4U0J. 

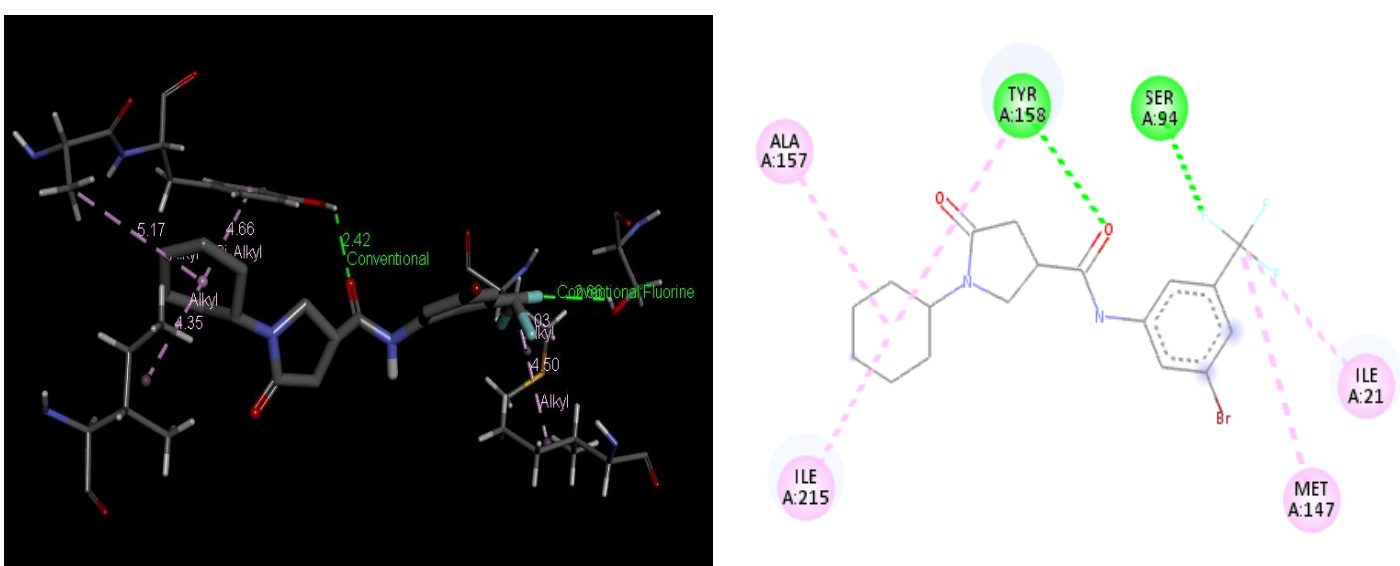

Figure 19. 3D and 2D diagram of CHEMBL386324 interaction with 4U0J.
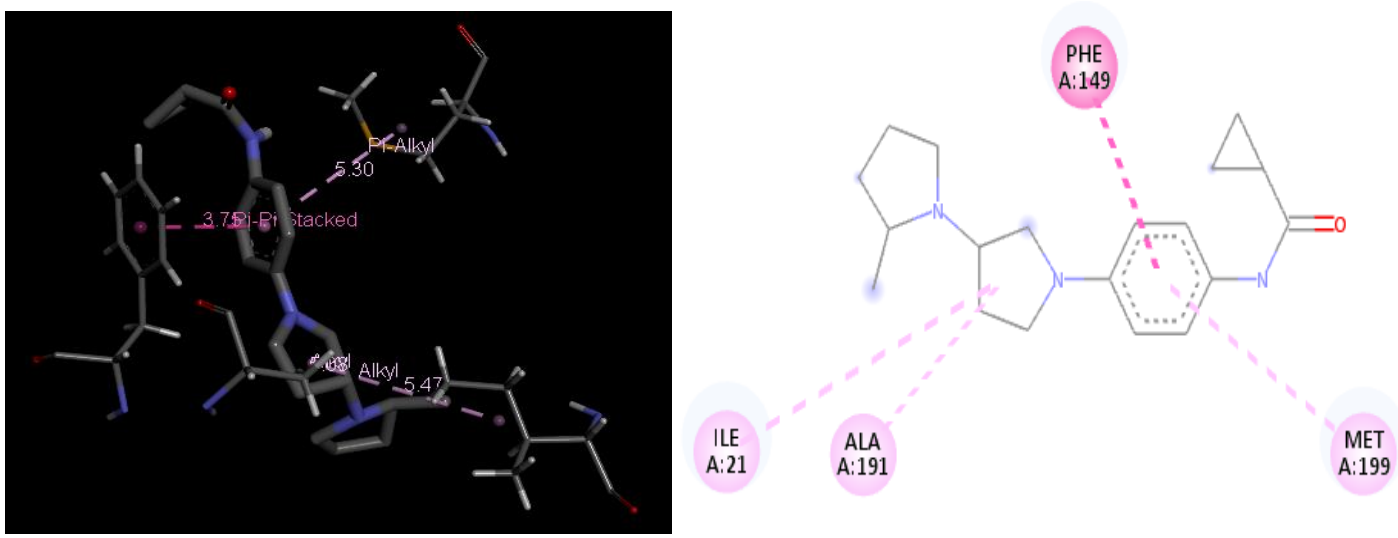

Figure 20. 3D and 2D diagram of CHEMBL2441646 interaction with 4U0J.
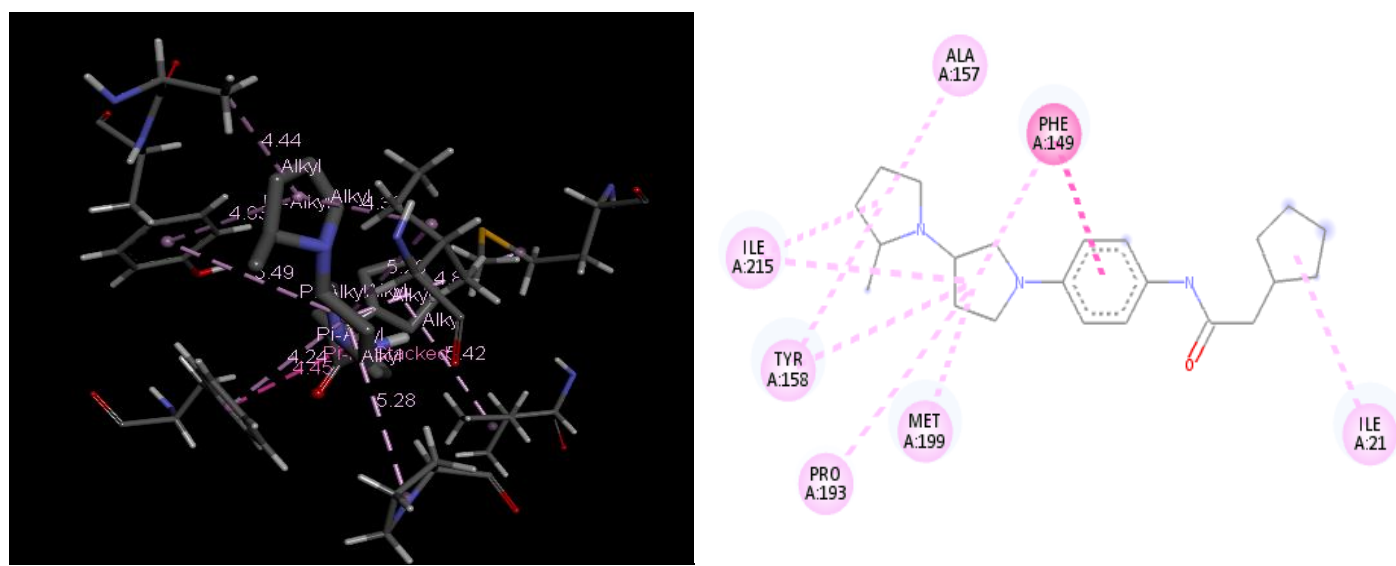

Figure 21. 3D and 2D diagram of CHEMBL2441653 interaction with 4U0J.
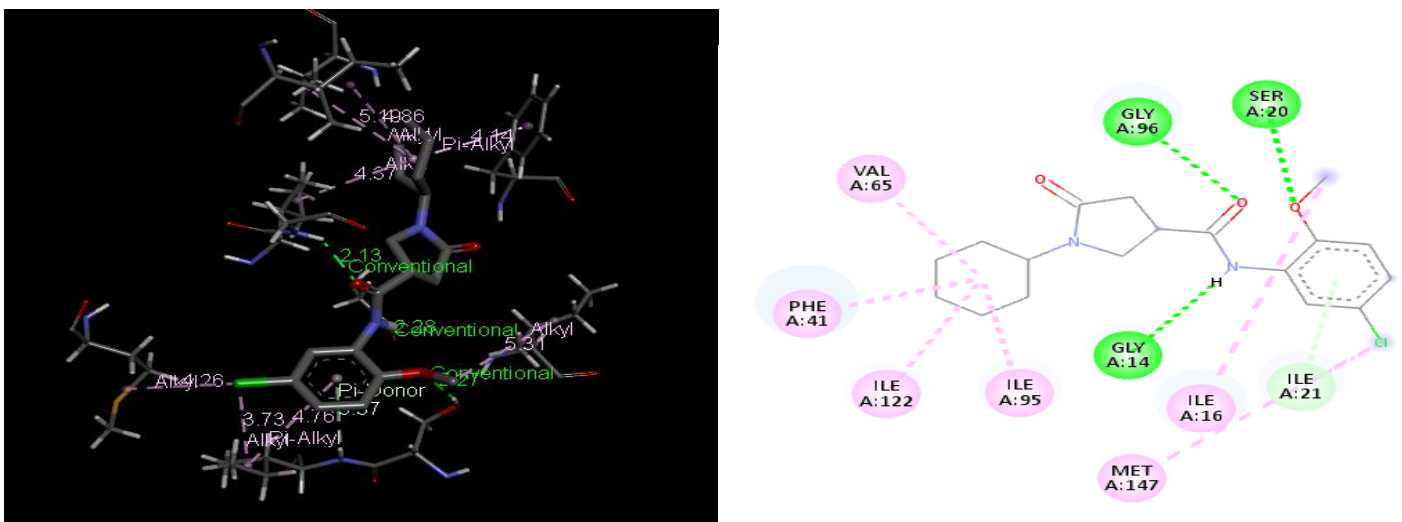

Figure 22. 3D and 2D diagram of CHEMBL384149 interaction with 4U0J. 

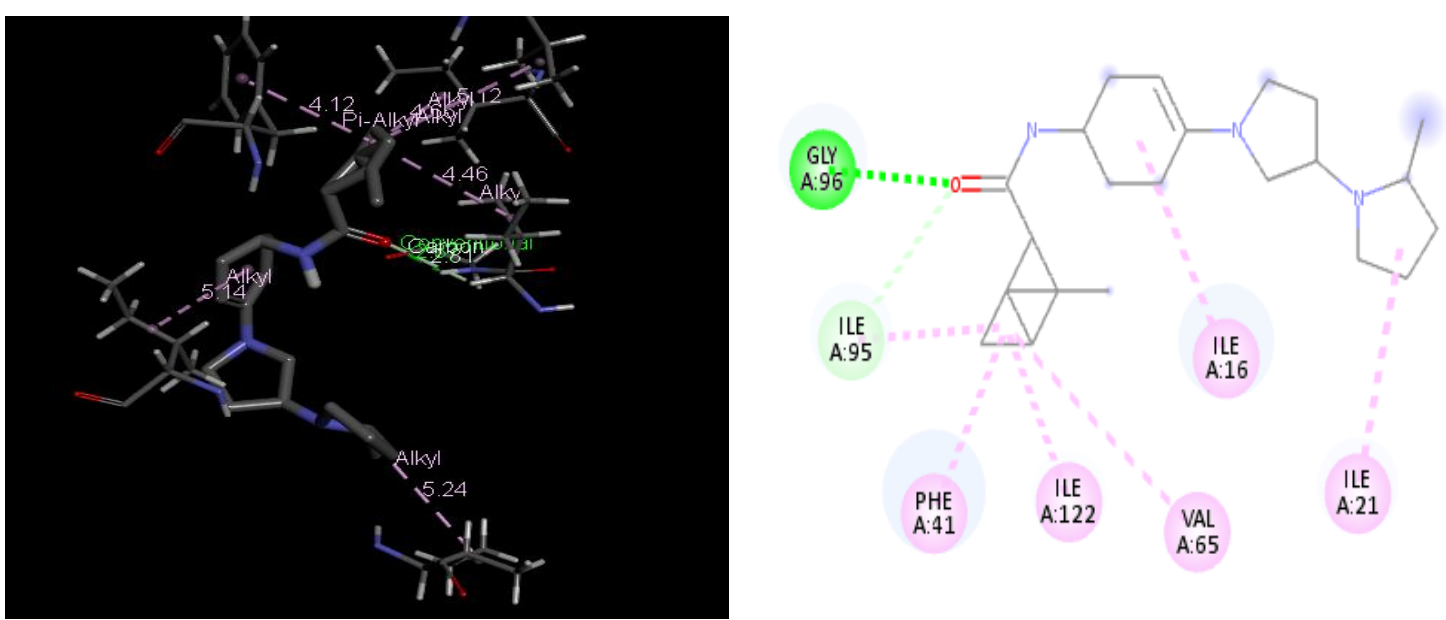

Figure 23. 3D and 2D diagram of CHEMBL2441650 interaction with 4U0J.
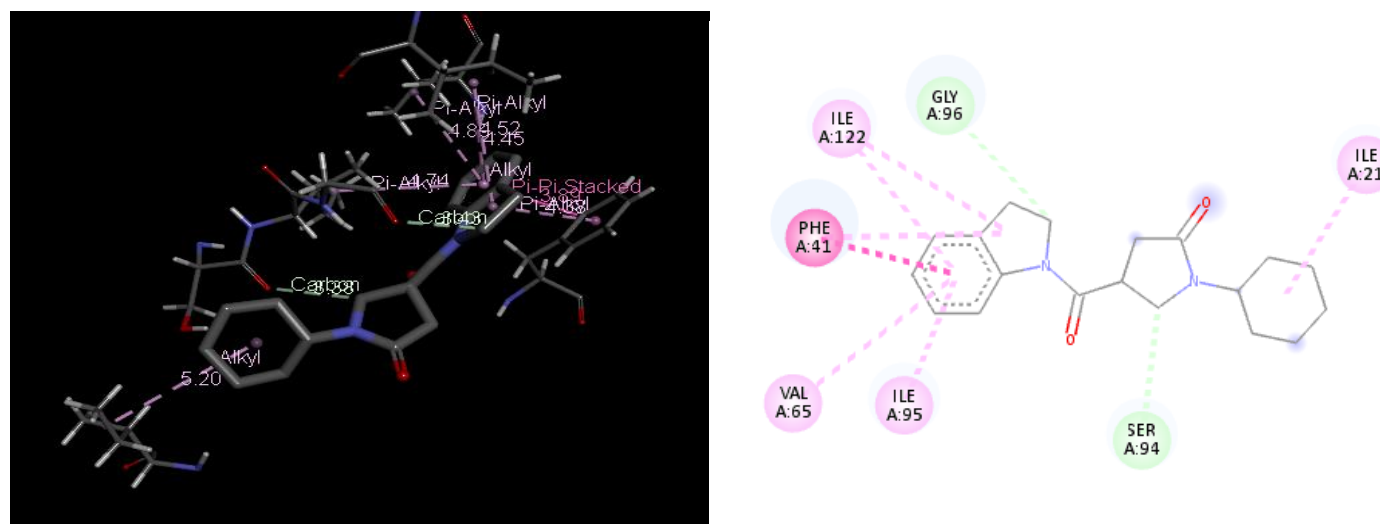

Figure 24. 3D and 2D diagram of CHEMBL217499 interaction with 4U0J.
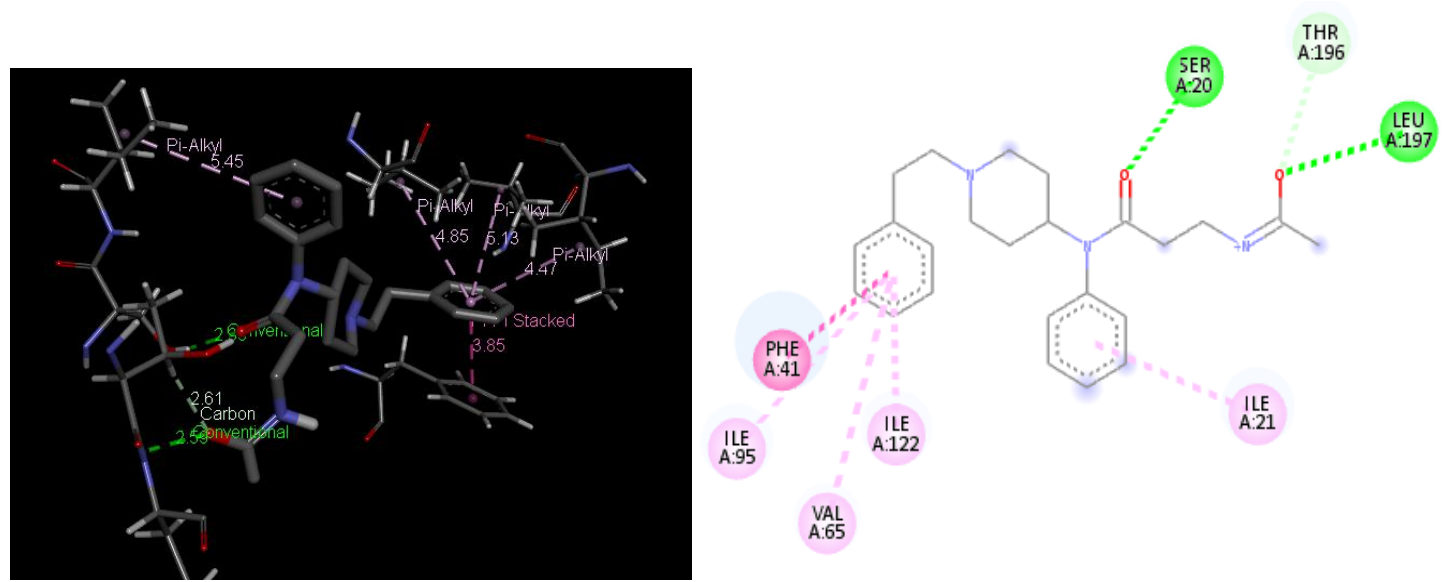

Figure 25. 3D and 2D diagram of CHEMBL386990 interaction with 4U0J.
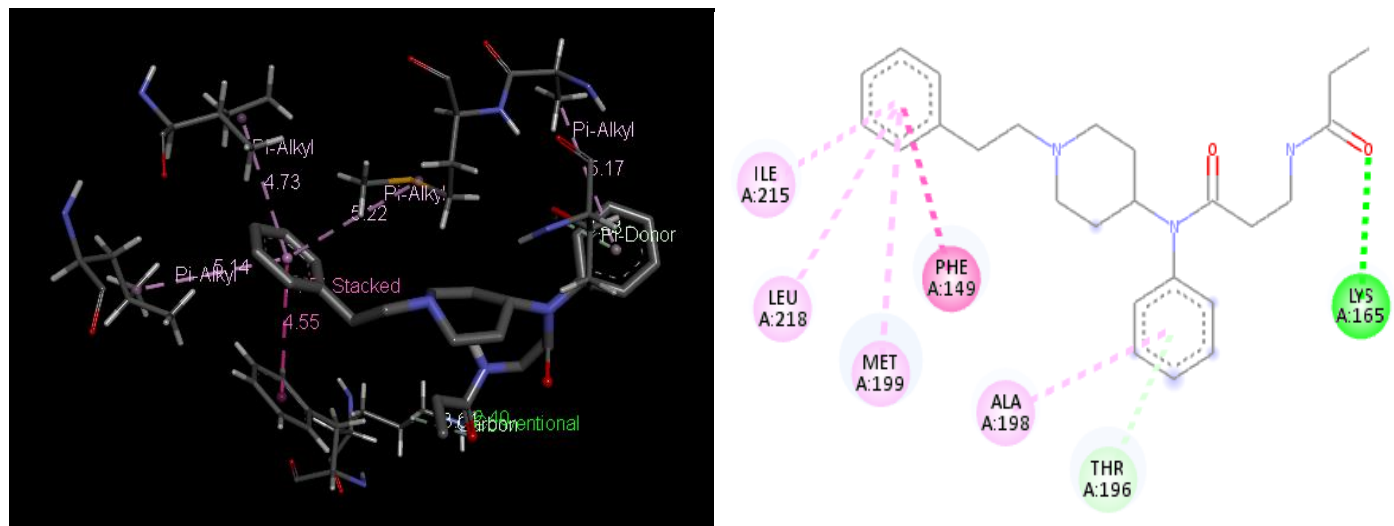

Figure 26. 3D and 2D diagram of CHEMBL241285 interaction with 4U0J. 

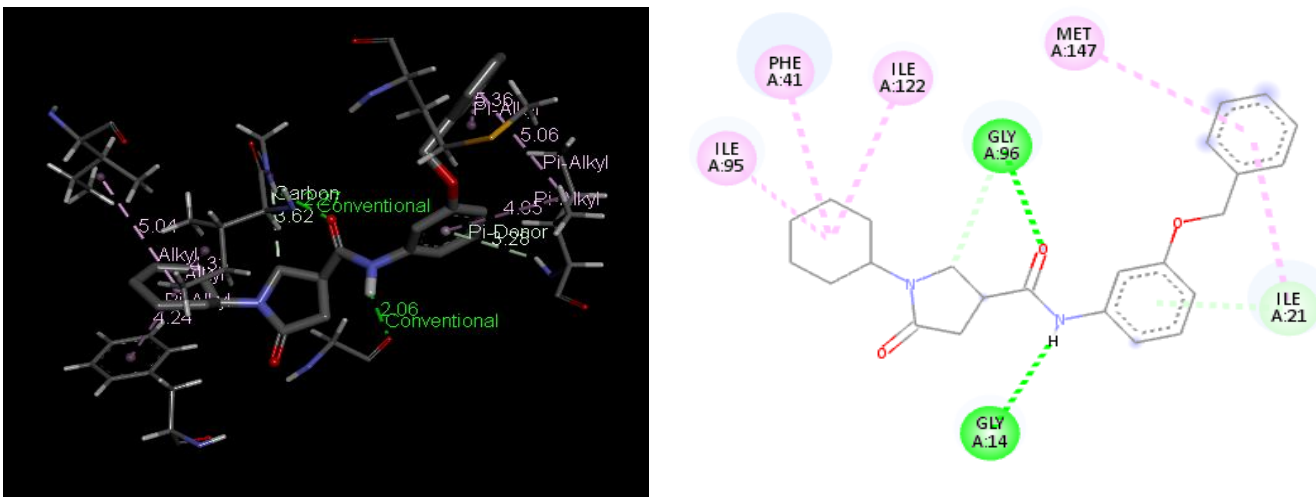

Figure 27. 3D and 2D diagram of CHEMBL424903 interaction with 4U0J.
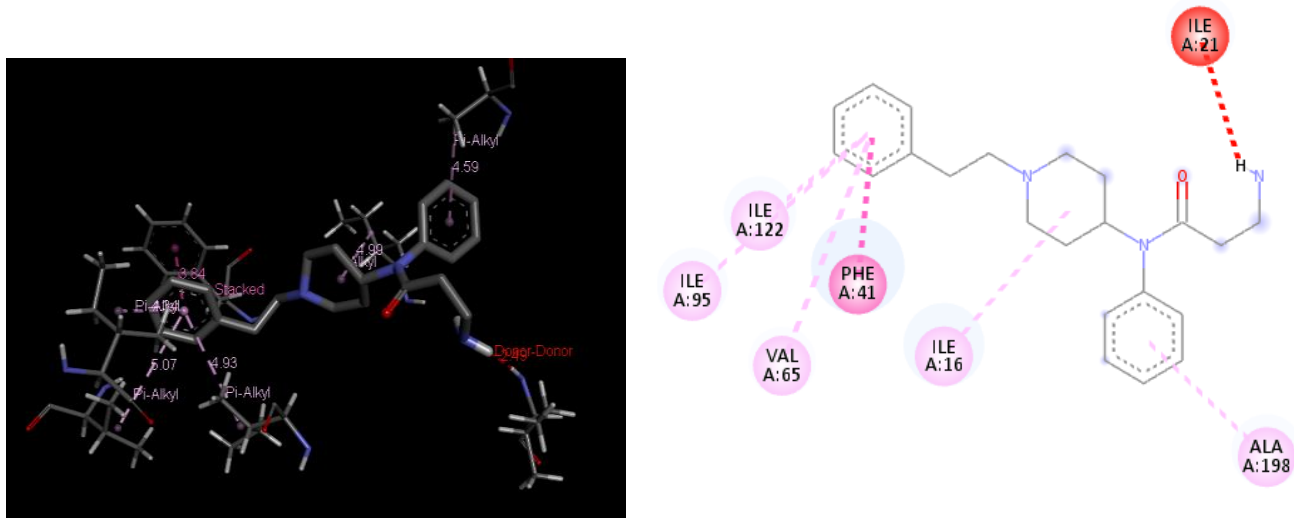

Figure 28. 3D and 2D diagram of CHEMBL385168 interaction with 4U0J.
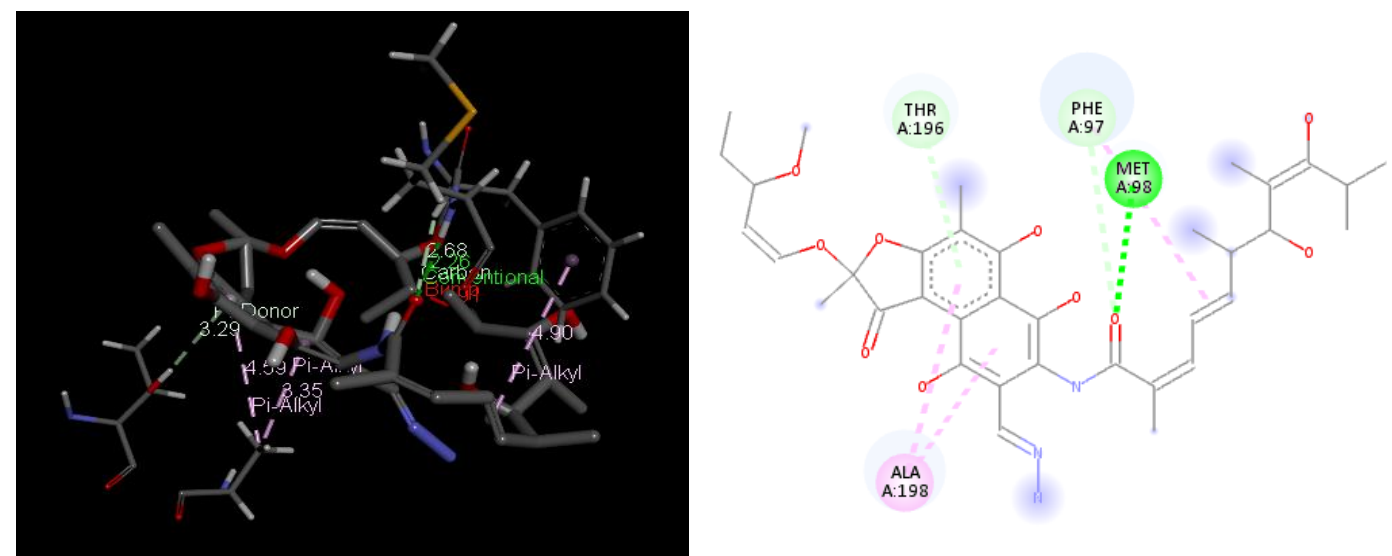

Figure 29. 3D and 2D diagram of Rifimpicin interaction with 4U0J.
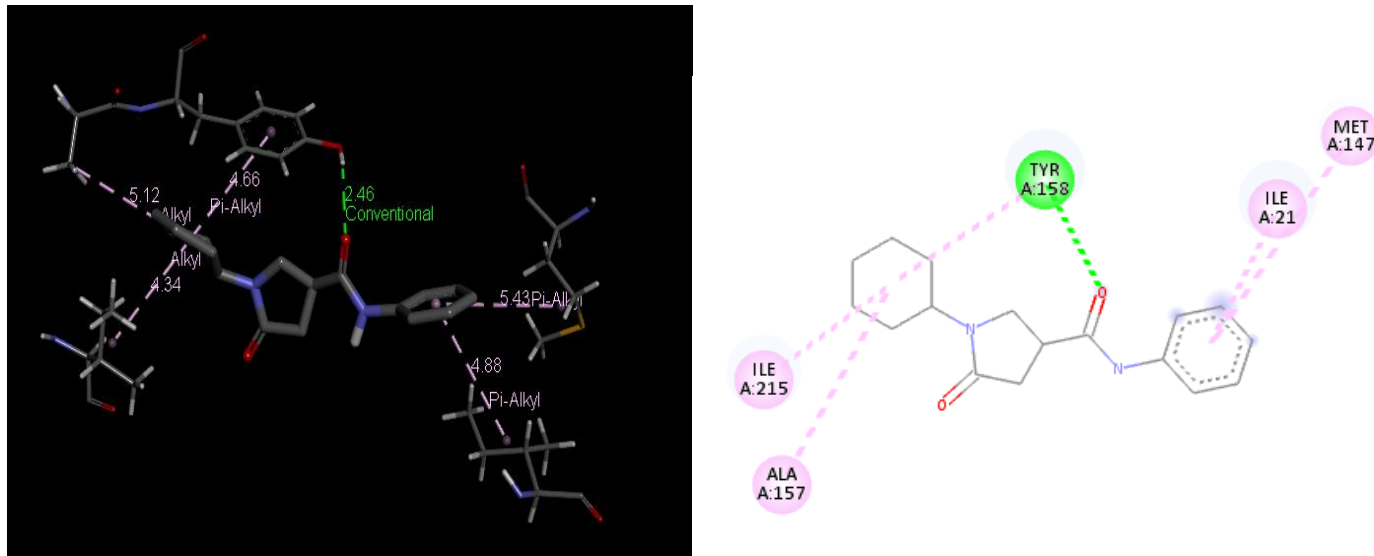

Figure 30. 3D and 2D diagram of Pyrrolidine carboxamides interaction with 4U0J. 
Tuberculosis is consequently contagious spreads by aerosols; thereby, newborn and immunocompromised patients are at high risk. Macrophages engulf these pathogens normally, and if they fail, mycobacterium can remain alive for years asymptomatically [1]. Resuscitation may occur anytime, and most cases $(80 \%)$ were reported as pulmonary tuberculosis. Researchers are trying to design and synthesize novel compounds that can simultaneously address mycobacterial and fungal infections in response to the demand for appropriate treatment. Due to the rise of antibiotic-resistant organisms, identifying drugs with good antitubercular activity is becoming increasingly important in tuberculosis research [10].

The goal of this research was to find chemicals that can bind to the 4U0J protein, which could be employed as a therapeutic medication for Mycobacterium tuberculosis in the future. Around 27 bioactive chemicals can bind to the 4U0J with docking scores ranging from -6.2 to $-11.2 \mathrm{Kcal} / \mathrm{mol}$ across the various compounds examined. CHEMBL424724 is a chemical compound whose IUPAC name is 2-cyclopentyl-N-[4-[3-(2-methylpyrrolidin-1-yl) pyrrolidin1 -yl] phenyl] acetamide was found best ligand to bind with the lowest energy $(-11.1 \mathrm{Kcal} / \mathrm{mol})$ with 4U0J (Fig 4, Table 3). CHEMBL441373 (-10.8 Kcal/mol) had the second-highest docking score (Fig 10, Table 3), whereas CHEMBL217852 $(-10.6 \mathrm{Kcal} / \mathrm{mol})$ received the thirdhighest docking score (Fig 4, Table 3), -9.2Kcal/mol, followed by CHEMBL216339 (-10.2 Kcal/mol) (Fig 11 and Table 3). CHEMBL217588 (Fig 4, Table 3), CHEMBL216807 (Fig 4, Table 1), and CHEMBL2441664 all had a docking score of $-9.2 \mathrm{Kcal} / \mathrm{mol}$ (Fig 17, Table 3). The docking scores of compounds CHEMBL385294 (Fig 3, Table 3), CHEMBL217499 (Fig 24, Table 3), and CHEMBL424903 (Fig 27, Table 1) were all $-9.9 \mathrm{Kcal} / \mathrm{mol}$. The other chemicals (Table 3) have a strong interaction with the 4U0J protein as well. During the global Mycobacterium tuberculosis outbreak, rifampicin and pyrrolidine carboxamides are being employed as drugs, along with numerous antiviral compounds (Fig 29, 30, Table 3). An attempt was made to anticipate this drug's binding mechanism and binding energy with respect to the 4U0J protein (rifampicin binding energy CHEMBL441373 -10.8 and Pyrrolidine carboxamides binding energy $-8.7 \mathrm{Kcal} / \mathrm{mol}$ ). Additionally, all compound agents were reported to limit viral replication and translation, which could considerably influence viral load reduction in infected people [7,8]. A compound like CHEMBL441373 was found to have exact similar binding energy $(-10.8 \mathrm{Kcal} / \mathrm{mol})$ compared to rifampicin, and this compound was found to have higher binding potential concerning Pyrrolidine carboxamide. All compounds studied here were found to have more negative binding potential energy compared to Pyrrolidine carboxamides except CHEMBL387284 (-8.4 Kcal/mol). Compound CHEMBL424724 has the lowest binding energy $(-11.1 \mathrm{~K} \mathrm{cal} / \mathrm{mol})$ compared to rifampicin, and this compound was found as the best molecule among all other compounds studied. All bioactive chemicals employed in this study satisfy the Lipinski rule of five, indicating that they can be used as therapeutics (Table 2). Our findings were similar with isoniazid derivatives and their antitubercular action [14] and with pyrrolidine carboxamides as a novel class of enoyl acyl carrier protein inhibitors [15].

PyRx is a computational therapeutic discovery virtual screening tool that can be used to analyze libraries of chemicals against prospective drug candidates. PyRx allows medicinal pharmacists to execute virtual screening from any environment, and it guides users through every phase of the way, from data pre-processing to job submission and evaluation. Although there is no miracle solution in the drug development process, PyRx features a docking method that focuses on simplicity, making it useful for computer-aided pharmaceutical research [16]. 
The provided results were classified as preliminary due to the small number of molecules investigated in this project; however, some conclusions might be reached. Due to the availability of improved molecular docking methods, larger virtual screening experiments focusing on small-molecule libraries with millions of compounds are available [17]. TB is a leading infectious killer worldwide, despite the availability of different chemotherapeutic treatments. This is primarily owing to a shortage of new medications, particularly those that are effective against MDR-TB and XDR-TB, as well as individuals who are HIV/AIDS coinfected [18]. Different new medications will be synthesized in the future to create new effective anti-TB molecules, based on the foregoing facts and inspired by the ongoing research on new derivatives, particularly in relation to mycobacterium chemotherapy [19]. Numerous challenges must surely be addressed, including the involvement of water molecules, solvent effects, entropic effects, and receptor flexibility [20]. There is now enough evidence to support the use of machine learning in drug design, and there is no longer any place for discussion about their efficacy and benefits in the direction of drug discovery [9].

Molecular docking, however, has several drawbacks, such as the lack of a universally applicable scoring mechanism that can successfully combine accuracy and speed [21]. Several enhancement guidelines, such as the usage of implicit solvent fashions and entropic factors, are being examined. Furthermore, given that ligands are normally dealt with in their whole, protein flexibility is only handled in part at best [22]. Further research is nevertheless essential to address this problem and deal with the induced-healthy issue. Furthermore, the dynamic involvement of water molecules throughout the docking process, in order to account for subsequently critical water-mediated hydrogen bond bridges between the drug and the receptor, may improve the approach's efficacy [9]. As of now, the outcomes of a docking test must be considered with caution and taken as a fantastic starting point for more significant investigation [23].

Several variables influence how the loose binding electricity $\left(\mathrm{G}_{\text {bind }}\right)$ is expressed within the shape of key variables, including electrostatic $\left(\mathrm{G}_{\text {elec }}\right)$, hydrogen bond $\left(\mathrm{G}_{\mathrm{hbond}}\right)$, torsional loose electricity $\left(\mathrm{G}_{\mathrm{tor}}\right)$, desolvation $\left(\mathrm{G}_{\text {desolv }}\right)$, dispersion, and repulsion $\left(\mathrm{G}_{\mathrm{vdw}}\right)$, as whole inner electricity $\left(\mathrm{G}_{\mathrm{total}}\right)$, and unbound electricity of the structure $\left(\mathrm{G}_{\mathrm{unb}}\right)$ [13]. As a result, a thorough understanding of the commonplace ethics guiding the prediction of loose binding electricity $\left(\mathrm{G}_{\text {bind }}\right)$ showing more warning indications of interacting molecules, is required so that solid docking approaches are achieved [24]. In addition, the docking approach aims to computationally simulate the technique of molecular identification and achieve a higher configuration to lower the system's overall loose electricity [25]. It could be very hard to find out a brand-new drug. In silico-chemico-organic processes are the principal bases of contemporary-day drug discovery [26].

In Silico ADME, Approaches have become a critical component of the drug development process [27]. This is in most cases because they could affect the complete drug improvement trajectory, figuring out and coming across new capability capsules with an enormous discount to value and time [28]. Besides that, computer-aided drug layout (CADD) schemes are critical for reducing the use of animals in vivo studies, assisting in the design of more protected pods, and readjusting regarded capsules, assisting pharmacological chemists at every phase (layout, discovery, improvement, and hit-optimization) of the screening of potential compounds [29]. On the one hand, conventional drug discovery strategies include the high-cost random screening of synthetic chemicals or natural preparations [30]. On the other hand, computational processes may be very multifarious, requiring interdisciplinary research 
and the software of CADD technological know-how to rationally layout powerful and commercially viable capsules [31]. CADD methodologies are gambling an ever-growing function in drug discovery which can be crucial inside the value-effective identification of promising drug candidates [32].

The results are based entirely on computer-assisted virtual screening. Depending on the outcomes of computational biology, it is found that all of the screened compounds with hydrogen bond(s) and steric interaction bonded to the binding pocket of $4 \mathrm{U} 0 \mathrm{~J}$ protein and rendered it inactive in this investigation. The process of developing new drugs is timeconsuming. As a result, pharmacological transposing may stop the spread of infectious diseases.

\section{Conclusions}

Molecular docking is one aspect of a novel new approach to researching the binding of tiny molecules to receptor proteins. The antituberculosis efficacy of triazole scaffolding in new therapeutic has been investigated. Compound CHEMBL441373 become located to possess maximum appropriate docking energy $(-11.1 \mathrm{Kcal} / \mathrm{mol})$, and it has become suitable as candidate molecules of cell wall protein inhibitor (4U0J). It should similarly be examined in vitro and in vivo situations further.

\section{Funding}

This research received no external funding.

\section{Acknowledgments}

This research has no acknowledgment.

\section{Conflicts of Interest}

The authors declare no conflict of interest.

\section{References}

1. Seki, M.; Choi, H.; Kim, K.; Whang, J.; Sung, J.; Mitarai, S. Tuberculosis: A persistent unpleasant neighbour of humans. Journal of Infection and Public Health 2021, 14, 508-513, https://doi.org/10.1016/j.jiph.2021.01.005.

2. Mittal, G.K.; Reddy, V.A.S.K.; Akhtar, S.M.; Kaur, H. Moxifloxacin induced encephalopathy in disseminated tuberculosis: A case report. Indian Journal of Tuberculosis 2020, 67, 423-425, https://doi.org/10.1016/j.ijtb.2020.05.002.

3. Laws, M.; Jin, P.; Rahman, K.M. Efflux pumps in Mycobacterium tuberculosis and their inhibition to tackle antimicrobial resistance. Trends in microbiology 2021, https://doi.org/10.1016/j.tim.2021.05.001.

4. Jiao, X.; Jin, X.; Ma, Y.; Yang, Y.; Li, J.; Liang, L.; Liu, R.; Li, Z. A comprehensive application: Molecular docking and network pharmacology for the prediction of bioactive constituents and elucidation of mechanisms of action in component-based Chinese medicine. Computational Biology and Chemistry 2021, 90, https://doi.org/10.1016/j.compbiolchem.2020.107402.

5. Thomas, L.; Birangal, S.R.; Ray, R.; Sekhar Miraj, S.; Munisamy, M.; Varma, M.; S.V, C.S.; Banerjee, M.; Shenoy, G.G.; Rao, M. Prediction of potential drug interactions between repurposed COVID-19 and antitubercular drugs: an integrational approach of drug information software and computational techniques data. Therapeutic Advances in Drug Safety 2021, 12, https://doi.org/10.1177/20420986211041277.

6. Alemu, A.; Aycheh, M.W.; Dilnessa, T. Tuberculosis and Human Immunodeficiency Virus Co-Infection and Associated Factors at Debre Markos Comprehensive Specialized Hospital, Northwest Ethiopia: A Four-Year Retrospective Study. HIV/AIDS (Auckland, NZ) 2021, 13, 293-299, https://doi.org/10.2147/HIV.S284034. 
7. Arshad, A.; Dayal, S.; Gadhe, R.; Mawley, A.; Shin, K.; Tellez, D.; Phan, P.; Venketaraman, V. Analysis of Tuberculosis Meningitis Pathogenesis, Diagnosis, and Treatment. Journal of Clinical Medicine 2020, 9 , https://doi.org/10.3390/jcm9092962.

8. Stelitano, G.; Sammartino, J.C.; Chiarelli, L.R. Multitargeting Compounds: A Promising Strategy to Overcome Multi-Drug Resistant Tuberculosis. Molecules 2020, https://doi.org/10.3390/molecules25051239.

9. Doğan, Ş.D.; Gündüz, M.G.; Doğan, H.; Krishna, V.S.; Lherbet, C.; Sriram, D. Design and synthesis of thiourea-based derivatives as Mycobacterium tuberculosis growth and enoyl acyl carrier protein reductase (InhA) inhibitors. European Journal of Medicinal Chemistry 2020, 199, https://doi.org/10.1016/j.ejmech.2020.112402.

10. Radan, M.; Ruzic, D.; Antonijevic, M.; Djikic, T.; Nikolic, K. In silico identification of novel 5-HT2A antagonists supported with ligand- and target-based drug design methodologies. Journal of Biomolecular Structure and Dynamics 2021, 39, 1819-1837, https://doi.org/10.1080/07391102.2020.1738961.

11. Parmar, R.G.; Shah, P.A.; Sailor, U.G.; Seth, K.A. In Silico Discovery of Novel Phytoconstituents of Amyris pinnata as a Mitotic Spindle Kinase Inhibitor. Current drug research reviews 2020, 12, 175-182, https://doi.org/10.2174/2589977512666200220122211.

12. Rehman, N.U.; Ansari, M.N.; Samad, A. In Silico, Ex Vivo and In Vivo Studies of Roflumilast as a Potential Antidiarrheal and Antispasmodic agent: Inhibition of the PDE-4 Enzyme and Voltage-gated Ca++ ion Channels. Molecules 2020, 25, https://doi.org/10.3390/molecules25041008.

13. Noh, M.A.A.; Rahiman, S.S.F.; Wahab, H.A.; Gazzali, A.M. Discovery of new targeting agents against GAPDH receptor for antituberculosis drug delivery. Journal of basic and clinical physiology and pharmacology 2021, 32, 715-722, https://doi.org/10.1515/jbcpp-2020-0435.

14. Kalani, K.; Chaturvedi, V.; Trivedi, P.; Tondon, S.; Srivastava, K.S. Dihydroartemisinin and its Analogs: A New Class of Antitubercular Agents. Current Topics in Medicinal Chemistry 2019, 19, 594-599, https://doi.org/10.2174/1568026619666190304142802.

15. Prasad, M.S.; Bhole, R.P.; Khedekar, P.B.; Chikhale, R.V. Mycobacterium enoyl acyl carrier protein reductase (InhA): A key target for antitubercular drug discovery. Bioorganic Chemistry 2021, 115, https://doi.org/10.1016/j.bioorg.2021.105242.

16. Cayona, R.; Creencia, E. Discovery of a "Cocktail" of Potential SARS-COV-2 Main Protease Inhibitors through Virtual Screening of Known Chemical Components of Vitex negundo L. (“Lagundi”). Medicinal Chemistry 2021, 17, 1-18, https://doi.org/10.2174/1573406417666210618132003.

17. Stokes, J.M.; Yang, K.; Swanson, K.; Jin, W.; Cubillos-Ruiz, A.; Donghia, N.M.; MacNair, C.R.; French, S.; Carfrae, L.A.; Bloom-Ackermann, Z.; Tran, V.M.; Chiappino-Pepe, A.; Badran, A.H.; Andrews, I.W.; Chory, E.J.; Church, G.M.; Brown, E.D.; Jaakkola, T.S.; Barzilay, R.; Collins, J.J. A Deep Learning Approach to Antibiotic Discovery. Cell 2020, 180, 688-702.e613, https://doi.org/10.1016/j.cell.2020.01.021.

18. Mupfumi, L.; Mpande, C.A.M.; Reid, T.; Moyo, S.; Shin, S.S.; Zetola, N.; Mogashoa, T.; Musonda, R.M.; Kasvosve, I.; Scriba, T.J.; Nemes, E.; Gaseitsiwe, S. Immune Phenotype and Functionality of Mtb-Specific T-Cells in HIV/TB Co-Infected Patients on Antiretroviral Treatment. Pathogens 2020, 9, https://doi.org/10.3390/pathogens9030180.

19. Teixeira, S.S.C.; Cerqueira, M.F.S.A.N.; Sousa, F.S. Multifunctional Enzymes as Targets for the Treatment of Tuberculosis: Paving the Way for New Anti-TB Drugs. Current Medicinal Chemistry 2021, 28, 58475882, https://doi.org/10.2174/0929867328666201229122722.

20. Beier, C.; Zacharias, M. Tackling the challenges posed by target flexibility in drug design. Expert Opinion on Drug Discovery 2010, 5, 347-359, https://doi.org/10.1517/17460441003713462.

21. Saikia, S.; Bordoloi, M. Molecular Docking: Challenges, Advances and its Use in Drug Discovery

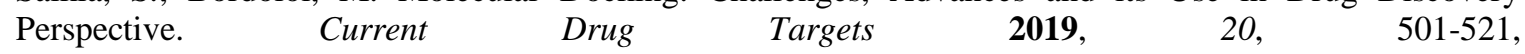
https://doi.org/10.2174/1389450119666181022153016.

22. Harmalkar, A.; Gray, J.J. Advances to tackle backbone flexibility in protein docking. Current Opinion in Structural Biology 2021, 67, 178-186, https://doi.org/10.1016/j.sbi.2020.11.011.

23. Chen, Y.-C. Beware of docking! Trends in Pharmacological Sciences 2015, 36, 78-95, https://doi.org/10.1016/j.tips.2014.12.001

24. Jose, G.; Suresha Kumara, T.H.; Nagendrappa, G.; Sowmya, H.B.V.; Sriram, D.; Yogeeswari, P.; Sridevi, J.P.; Guru Row, T.N.; Hosamani, A.A.; Sujan Ganapathy, P.S.; Chandrika, N.; Narendra, L.V. Synthesis, molecular docking and anti-mycobacterial evaluation of new imidazo[1,2-a]pyridine-2-carboxamide derivatives. European Journal of Medicinal Chemistry 2015, 89, 616-627, https://doi.org/10.1016/j.ejmech.2014.10.079.

25. Shahbaaz, M.; Qari, S.H.; Abdellattif, M.H.; Hussien, M.A. Structural analyses and classification of novel isoniazid resistance coupled mutational landscapes in Mycobacterium tuberculosis: a combined molecular docking and MD simulation study. Journal of Biomolecular Structure and Dynamics 2020, 1-10, https://doi.org/10.1080/07391102.2020.1861986.

26. Manyeruke, M.H.; Tshiwawa, T.; Hoppe, H.C.; Isaacs, M.; Seldon, R.; Warner, D.F.; Krause, R.W.M.; Kaye, P.T. Synthesis and biological evaluation of bis-N2,N2'-(4-hydroxycoumarin-3-yl)ethylidene]-2,3- 
dihydroxysuccinodihydrazides. Bioorganic \& Medicinal Chemistry Letters 2020, 30, https://doi.org/10.1016/j.bmcl.2019.126911.

27. Das, T.; Mehta, C.H.; Nayak, U.Y. Multiple approaches for achieving drug solubility: an in silico perspective. Drug Discovery Today 2020, 25, 1206-1212, https://doi.org/10.1016/j.drudis.2020.04.016.

28. Chacko, A.; Wen, S.C.H.; Hartel, G.; Kapur, N.; Wainwright, C.E.; Clark, J.E. Improved Clinical Outcome After Treatment of Mycobacterium abscessus Complex Pulmonary Disease in Children With Cystic Fibrosis. The Pediatric Infectious Disease Journal 2019, 38, 660-666, https://doi.org/10.1097/INF.0000000000002274.

29. Moretti, L.; Sartori, L. A Simple and Resource-efficient Setup for the Computer-aided Drug Design Laboratory. Molecular Informatics 2016, 35, 489-494, https://doi.org/10.1002/minf.201600025.

30. Macalino, S.J.Y.; Billones, J.B.; Organo, V.G.; Carrillo, M.C.O. In Silico Strategies in Tuberculosis Drug Discovery. Molecules 2020, 25, https://doi.org/10.3390/molecules25030665.

31. Ye, Q.; Chai, X.; Jiang, D.; Yang, L.; Shen, C.; Zhang, X.; Li, D.; Cao, D.; Hou, T. Identification of active molecules against Mycobacterium tuberculosis through machine learning. Briefings in Bioinformatics 2021, 22, https://doi.org/10.1093/bib/bbab068.

32. Munnaluri, R.; Reddy Peddi, S.; Kanth Sivan, S.; Manga, V. Computational studies on N-phenyl pyrrole derivatives as MmpL3 inhibitors in Mycobacterium tuberculosis. Computational Biology and Chemistry 2019, 78, 81-94, https://doi.org/10.1016/j.compbiolchem.2018.11.007. 